\title{
Implementing a New Formulation in WRF-LES for Buoyant Plume Simulations: bPlume-WRF-LES Model
}

\author{
SUDHEER R. BHIMIREDDY ${ }^{\mathrm{a}, \mathrm{b}}$ AND KIRAN BHAGANAGAR ${ }^{\mathrm{a}}$ \\ ${ }^{\mathrm{a}}$ The University of Texas at San Antonio, San Antonio, Texas \\ ${ }^{\mathrm{b}}$ Illinois State Water Survey, Prairie Research Institute, University of Illinois at Urbana-Champaign, Urbana, Illinois
}

(Manuscript received 15 June 2020, in final form 26 April 2021)

\begin{abstract}
A new formulation-bPlume-WRF-LES model-was implemented within the Weather Research and Forecasting (WRF) Model to simulate the two-way coupling between the atmospheric boundary layer (ABL) and gas plume (denser and lighter) released into the atmosphere. The existing WRF large-eddy simulation (WRF-LES) modeling system was modified by coupling an additional transport equation for the plume gas mixture and by accounting for the buoyant production term in the turbulence kinetic energy equation. The focus of the work was to understand the effect of atmospheric forcings on plume rise, plume mixing, and plume dynamics during the early stages of plume development. For this purpose, the bPlume-WRF-LES model was used to simulate the release of buoyant plumes from a large area source into different atmospheric conditions with varying stratification and mean wind forcing values. Plumes released in a convective ABL background rise according to the $2 / 3$ power law with time before reaching the boundary layer top and spreading laterally. The convective ABL eddy turnover time scale $\left(t_{*}\right)$ dictates the rate at which plume mixes with the ambient air inside the convective boundary layer (CBL) and the plume dilution rate scales as $t_{*}^{-3 / 2}$. Both the stratification and wind forcing enhance the plume mixing from the early plume development stage, and dilute the plume much faster. An increase in the mean winds within the CBL contributes to uniform mixing and greater bent-over plume behavior at a shorter downwind distance from the source.
\end{abstract}

KEYWORDS: Turbulence; Plumes; Buoyancy; Entrainment; Large eddy simulation; Atmosphere; Transport

\section{Introduction}

The release of hazardous or contaminant gases in the atmosphere from naturally occurring extreme events (Reid et al. 2016), or accidental release from industries (Sklavounos and Rigas 2006; Khan et al. 2015), or man-made release (Dolgin 2013; Bhaganagar and Bhimireddy 2017, 2020b) is of great relevance to public health and security. Often, such releases are buoyant in nature, such as smoke release from wildfires (Bowman and Johnston 2005; Lareau and Clements 2017), pyroclastic flow from volcanic eruptions, or release of hot pollutant gases released from various sources (Leelössy et al. 2014). Buoyant plumes released into the convective boundary layer (CBL) are significantly influenced by the dynamics of the atmospheric boundary layer (ABL). In particular, under the influence of upward sensible surface heat flux $H_{0}$, the CBL is dominated by the competing roles of shear- and buoyancy forcings (Kaimal et al. 1976; Kim et al. 2003; Salesky et al. 2017). From previous works such as that of Deardorff (1970) and Panofsky et al. (1977) and others, CBL forcings are well represented by Monin-Obukhov length scale $L$, mixing layer height $z_{i}$, convective velocity scale $w_{*}$, and friction velocity $u_{*}$ due to the surface shear stress. Pasquill (1961) defined discrete stability classes using the incoming solar radiation and wind speed to define the degree of atmospheric stability. Later, Golder (1972) derived a relation between $z_{0} / L$ and the Pasquill stability classes, where $z_{0}$ is the surface roughness length. Van Ulden and Holtslag (1985) and Holtslag and Nieuwstadt (1986)

Corresponding author: Kiran Bhaganagar, kiran.bhaganagar@ utsa.edu identified the key parameters that govern the diffusion of a scalar in a CBL as $z_{i} / L$, and $u_{*} / w_{*}$. The presence of shear in $\mathrm{CBL}$ alters the turbulence structure inside the boundary layer, in fact, the additional buoyancy present in a CBL lifts the streaky structures from the shear forcings resulting in the formation of convective rolls (Moeng and Sullivan 1994). Buoyant plumes released into the atmosphere interact with their surroundings as the ambient fluid is injected into the plume resulting in the dispersion and dissipation of the plume (Woods 2010), subject to atmospheric forcings. Thus, the atmospheric boundary layer dictates the dynamic behavior of buoyant plumes.

Under convective atmospheric conditions, when Earth's surface is continuously heated by the incident solar radiation, buoyant plume motion is further affected by the presence of coherent structures (often termed as thermal eddies) in the atmosphere. While the background atmospheric turbulence aids in plume diffusion, under low wind speeds it can be sporadic and often results in a "looping" plume pattern that brings high-concentration pockets closer to the ground (Bierly and Hewson 1962). If the buoyancy of the source is high enough, the plume rises to the top of the convective boundary layer (CBL) and "lofts" until the convective motions mix it downward (Willis and Deardorff 1983). Under extreme source conditions, where the source buoyancy is really strong (as in the case of large-area wildfires), the plume can even penetrate the CBL top and get trapped, until it can be re-entrained due to the CBL growth (Briggs 1984; Weil et al. 2012). The intensity of this updraft buoyant motion depends on the size and type of buoyant source and the stability potential of the atmosphere. To quantify this upward motion with respect to the background atmospheric state, plume rise-the height above the source 
reached by the plume due to the momentum and buoyancy at the source (Briggs 1984) - is often used as a valuable metric. The plume rise and mixing are commonly characterized in terms of reduced gravity parameter, which is defined as: $g^{\prime}=$ $g\left(\rho_{a}-\rho_{p}\right) / \rho_{a}$, (Morton 1957), where $g$ is the gravitational constant, and $\rho_{a}$ and $\rho_{p}$ are the densities of the ambient air and plume, respectively.

The plume rise and mixing of buoyant plumes released in CBL have been studied using laboratory-scale experiments (Willis and Deardorff 1983, 1987; Weil et al. 2002), numerical modeling (Weil et al. 1997; Van Dop 1992), and field observations Bowne and Londergan (1983); Murray and Bowne (1988). In light of the recent findings, though experiments and numerics have contributed to our understanding of plume dynamics, there are still fundamental questions that have yet to be answered. In particular, simulating the dynamic interactions of plume with the ABL is still a challenging task. The ABL dynamics can be simulated using numerical weather prediction (NWP) models such as the Advanced Research version of the Weather Research and Forecast (WRF-ARW) Model (Skamarock et al. 2005), which can represent motions in the atmosphere ranging from a few meters to global scales (Michalakes et al. 2005; Powers et al. 2017). However, the dispersion of plume released into the $\mathrm{ABL}$ is represented as passive tracers in the current WRF-LES formulation (see e.g., Nottrott et al. 2014; Nunalee et al. 2014; Bhimireddy and Bhaganagar 2018b).

The existing WRF-LES dispersion model does not account for the buoyant forcing of plumes and the buoyant production of turbulence kinetic energy (TKE) generated by the plumes. Alternatively, the existing transport and dispersion models use the model output from NWP models and Briggs plume rise formulas (Briggs 1965, 1984) to estimate the final plume rise. Some examples of such dispersion models are Hybrid Single Particle Lagrangian Integrated Trajectory (HYSPLIT) (Stein et al. 2015), American Meteorological Society/Environmental Protection Agency Regulatory Model (AERMOD) (Cimorelli et al. 2005), and Flexible Particle dispersion (FLEXPART) (Stohl et al. 2005). To address the use of simplified plume rise equations in the case of wildfire emission modeling, researchers have developed models like Active Tracer HighResolution Atmospheric Model (ATHAM) (Oberhuber et al. 1998; Trentmann et al. 2006), WRF-Sfire (Mandel et al. 2014), and WRFSC (Kochanski et al. 2016). These models use either prescribed (ATHAM) or in-model predicted (WRF-Sfire and WRFSC) heat and emission fluxes to add buoyancy forcing. However, the buoyancy of the emission gases is not considered; rather these emissions are represented as passive tracers. This has a limitation when the emissions are released without the additional heat, such as, the Lake Nyos disaster in Cameroon 1986 when a large $\mathrm{CO}_{2}$ bubble from Lake Nyos spread across the surrounding area (Kling et al. 1987).

The recent observational studies of Adams et al. (2019) and Andreae (2019) revealed elevated levels of gases such as CO, $\mathrm{NH}_{3}$ and $\mathrm{NO}_{2}$ within the plumes emitted from wildfires. The long-range transport of these gases can impact the air quality of regions that are otherwise free of particulate matter. For instance, Lutsch et al. (2016, 2019) observed elevated levels of
$\mathrm{NH}_{3}$ in high Arctic regions as a result of the Canadian boreal wildfires. The elevations to which these gaseous plumes are injected into the atmosphere effect the way they are dispersed, making it crucial to understand the effects of atmospheric conditions on the plume rise. With the model developed in this study, it is possible to study the behavior of such gases without the need to solve the fire parameters (given that the fluxes are known) and more importantly, the two-way feedback, (i.e., the effect of plumes on the atmospheric state) is possible. To address these challenges, we modified the WRF-LES formulation to introduce the buoyant coupling between the plume and ABL.

The objectives of the present study were:

1) to develop a new bPlume-WRF-LES formulation within the WRF framework that accounts for the two-way coupling between the ABL and the buoyant plume by accounting for the buoyancy forcings and the buoyant TKE production generated by the plume; and

2) to use the new bPlume-WRF-LES model to understand the effect of atmospheric unstable stratification effects and the wind forcings on plume dispersion processes, and to answer the following scientific questions: (i) What is the effect of the shear and buoyancy forcings of the CBL on plume rise and mixing? (ii) What is the contribution of atmospheric forcings on plume penetration through the CBL top?

In this study, $\mathrm{NH}_{3}$ plumes were released into the $\mathrm{CBL}$ from an area source on the ground to understand the influence of $\mathrm{ABL}$ forcings on (i) plume rise, (ii) plume mixing, and (iii) plume penetration through the CBL top. The role of CBL forcings on $\mathrm{NH}_{3}$ plumes was investigated in three different background CBL forcings, namely: 1) a baseline case of calm air with no stratification; 2) an unstable stratified boundary layer with weak and moderate surface heat forcing; and 3) a convective boundary layer with weak and strong mean winds. We characterize the plume in terms of reduced gravity $g^{\prime}$ (hereinafter, plume concentration). We defined plume rise as the farthest point reached by the plume vertical to ground. A threshold value of $1 \%$ of the source strength was used to define the plume interface.

The rest of the manuscript is arranged as follows: section 2 presents the modifications done to the WRF-ARW Model. Section 3 gives a brief review of existing literature for plumes and their characteristics. Section 4 presents the case study of our baseline simulation, where $\mathrm{NH}_{3}$ is released into a uniform atmosphere with no stratification. Section 5 presents the results of the release of $\mathrm{NH}_{3}$ in unstable stratification but with no mean wind. Section 6 presents the results of the release of $\mathrm{NH}_{3}$ in a CBL with different wind forcings and surface heating. The summary and discussion are presented in section 7 .

\section{2. bPlume-WRF-LES model implementation in WRF}

\section{a. Governing equations}

The bPlume-WRF-LES model implemented within WRF is discussed in this section. The basic governing equations solved in the existing WRF-ARW are fully compressible Euler nonhydrostatic equations in flux form (Skamarock et al. 2005). 
Using WRF's modular architecture, it is straightforward to implement new schemes and parameterizations inside WRF framework (Grell et al. 2005; Coen et al. 2013; Burton et al. 2017). The basic governing equations in WRF are as follows:

$$
\begin{aligned}
\frac{\partial \mu}{\partial t}+\nabla \cdot \mathbf{V} & =0, \\
\frac{\partial U}{\partial t}+\nabla \cdot(\mathbf{V} u)+\mu \alpha \frac{\partial p}{\partial x} & =F_{U}, \\
\frac{\partial V}{\partial t}+\nabla \cdot(\mathbf{V} v)+\mu \alpha \frac{\partial p}{\partial y} & =F_{V}, \\
\frac{\partial W}{\partial t}+\nabla \cdot(\mathbf{V} w)+\mu \alpha \frac{\partial p}{\partial z} & =F_{W}-\mu g, \\
\frac{\partial \Theta}{\partial t}+\nabla \cdot(\mathbf{V} \theta) & =F_{\Theta},
\end{aligned}
$$

where $\mu=p_{h s}-p_{h t}$ represents the mass of air per unit area in the modeled atmospheric column, $p_{h s}$ and $p_{h t}$ are the hydrostatic pressures at the surface and top of the atmospheric column. The term $\mu$ is the vertical coordinate metric used to convert the prognostic variables into their flux form, $\mathbf{V}=(U, V$, $W)=\mu(u, v, w)$ represents the horizontal $(u, v)$ and vertical $(w)$ velocities, $p$ is the pressure, $\Theta=\mu \theta$ with $\theta$ as the potential temperature, $\alpha$ is the inverse density, and $g$ is acceleration due to gravity. The forcing terms $F_{U}, F_{V}, F_{W}$, and $F_{\theta}$ represent model physics, turbulent mixing, and Earth's rotation. More details about the forcing terms are given in Skamarock et al. (2005). The term, $\mu g$, on the right-hand side of Eq. (4) represents buoyancy forcing.

To simulate a continuous buoyant plume, an additional equation for gas-mixture ratio variable $q_{p}\left(\mathrm{~kg} \mathrm{~kg}^{-1}\right)$ is introduced in the WRF Model by adding Eq. (6) to the existing framework as follows:

$$
\frac{\partial\left(\mu q_{p}\right)}{\partial t}+\nabla \cdot \mathbf{V} q_{p}=F_{Q}
$$

where $F_{Q}$ includes the turbulent mixing and source term [= $\left.\mu\left(\partial Q_{p} / \partial z\right)\right]$ forcings, and $Q_{p}$ is the gas-mixture surface-flux specified as an input to the WRF Model.

For dry atmosphere at rest, the inverse density inside model domain becomes $\alpha=\alpha_{d}=1 / \rho_{d}$, where $\rho_{d}$ is the density of dry air. Introducing a buoyant plume of density $\rho_{d}$ into the model results in an additional buoyancy forcing of the form $\rho_{p} q_{p} g$ and the inverse density becomes $\alpha=1 /\left(\rho_{d}+\rho_{p} q_{p}\right)$. The plume density $\rho_{p}$ at standard atmospheric pressure $p_{0}$ and temperature $T_{0}$ is estimated during the model initializing phase using the equation, $\rho_{p}=p_{0} / R_{p} T_{0}$, where $R_{p}$ is the plume gas constant and the final mixture density is obtained by multiplying the plume density with the plume mixing ratio $q_{p}$. Following Dalton's law of partial pressures, the full pressure $p$ in the model is estimated as the sum of partial pressures, i.e., $p=p_{d}+$ $q_{p} p_{p}$, where the partial pressures, $p_{d}$ of dry air and $p_{p}$ of plume are calculated from equation of state. These equations for total buoyancy forcing and pressure are similar in form to those used for studying atmosphere with water vapor (Bannon 2002; Bryan and Fritsch 2002) and analogous to the WRF framework for including moisture in the model (Skamarock et al. 2005).

\section{b. Turbulence closure in WRF-LES}

For estimating the eddy viscosity coefficients used in the turbulent mixing tendencies that are part of right-hand-side forcing terms in Eqs. (2)-(6), we used the 1.5-order turbulence kinetic energy (TKE) scheme in WRF, based on the sensitivity tests performed in Bhimireddy and Bhaganagar (2018a). The prognostic equation for subgrid TKE $e$ is as follows:

$$
\frac{\partial \mu_{d} e}{\partial_{t}}+\nabla \cdot(\mathbf{V} e)=\mu_{d}\left[P_{s}+P_{b}+P_{d}\right],
$$

here, $P_{s}, P_{b}$ and $P_{d}$ represent the shear production, buoyant production and dissipation of TKE and are given by

$$
\begin{aligned}
P_{s}= & K_{h}\left\{\left(\frac{\partial u}{\partial x}\right)^{2}+\left(\frac{\partial v}{\partial y}\right)^{2}+\left(\frac{\partial u}{\partial y}+\frac{\partial v}{\partial x}\right)^{2}\right\} \\
& +K_{v}\left\{\left(\frac{\partial w}{\partial z}\right)^{2}+\left(\frac{\partial w}{\partial x}+\frac{\partial u}{\partial z}\right)^{2}+\left(\frac{\partial w}{\partial y}+\frac{\partial v}{\partial z}\right)^{2}\right\} \\
P_{b}= & -K_{v} g\left(\frac{1}{\theta} \frac{\partial \theta}{\partial z}-\frac{\partial q_{p}}{\partial z}\right) \\
P_{d}= & -\frac{C e^{3 / 2}}{l}
\end{aligned}
$$

and

$$
C=1.9 C_{k}+\frac{\max \left[0,0.93-1.9 C_{k}\right] l}{\Delta s}
$$

where $\Delta s=\sqrt[3]{\Delta x \Delta y \Delta z}, l=\min [\Delta s, 0.76 \sqrt{e} / N]$ is the mixing length, where $N$ is Brunt-Väisälä frequency and $C_{k}$ is a constant $(=0.1)$. The eddy viscosities in horizontal $\left(K_{h}\right)$ and vertical $\left(K_{v}\right)$ are computed as

$$
K_{h, v}=C_{k} l_{h, v} \sqrt{e} .
$$

Estimation of the length scale in the horizontal and vertical is dependent on the Brunt-Väisälä frequency (Skamarock et al. 2005). For the scalars present in the model, their eddy viscosities for mixing are obtained by multiplying $K_{h, v}$ by the inverse Prandtl number, which is computed as $\operatorname{Pr}^{-1}=1+2 l / \Delta s$.

In summary, Eq. (6) is coupled to the existing governing equations. The buoyancy forcing term in Eq. (4) is updated once the plume is released into the model domain. It should be noted that the buoyancy production term $P_{b}$ in Eq. (7) is modified by accounting for the vertical gradient of newly added gas-mixture mixing ratio. The modified WRF-bPlume source code is available online at https:/github.com/CFD-UTSA/ bplume-WRF.

\section{Plume characteristics}

\section{a. Plume rise}

The experiments by Willis and Deardorff (1983, 1987) demonstrated that the buoyant plume behavior inside the $\mathrm{CBL}$ can be characterized by a nondimensional buoyancy flux parameter $F_{*}$ given as follows: 


$$
F_{*}=\frac{B_{0}}{\bar{U} w_{*}^{2} z_{i}} .
$$

Their experiments showed that for sufficiently high source buoyancy, when $F_{*} \geq 0.1$, the buoyant plumes can reach the CBL top and loft there before mixing downward due to the convective motions present in the CBL. In this study, an approach similar to that of Weil et al. (2002) was adopted where $F_{*}=B_{0} /\left(w_{*}^{3} z_{i}\right)$ for the cases where $U=0$. In the present study, $F_{*}$ was varied from 0.17 to 9.6 . As will be shown later, all the buoyant plumes simulated lofted near the CBL top, thus showing the validity of the lower threshold of $F_{*} \geq 0.1$ as per Willis and Deardorff (1987).

Following the approach of Slawson and Csanady (1967) and using the basic governing equations of Morton et al. (1956) for a buoyant plume, the trajectory of a bent-over plume can be analyzed. Using the assumption that the wind speed $U$ is constant, that the plume cross-section variables follow a top-hat profile and that plume growth could be characterized using an entrainment coefficient $\alpha$, the mass, momentum, and energy balance equations for a plume element can be written as follows:

$$
\begin{aligned}
& U \frac{d R}{d x}=\alpha \frac{M}{U R^{2}}, \\
& \frac{d M}{d x}=R^{2} g^{\prime}=\frac{B}{U}, \\
& \frac{d B}{d x}=-N^{2} \frac{M}{U},
\end{aligned}
$$

where $R$ is the plume element radius, $M=U R^{2} w$ is the momentum flux, $B=R^{2} U g^{\prime}$ is the buoyancy flux, $w$ is the vertical velocity and $g^{\prime}$ is buoyancy deficit. Using the kinematic relation $d z / d x=w / u$ and initial conditions of $R=R_{0}, B=B_{0}, M=M_{0}$ and $z=0$ at the source, i.e., $x=0$, the location of the plume centerline at any given downwind distance can be found by solving Eqs. (14)-(16):

$$
z(x)=\left\{\frac{3}{2 \alpha^{2}}\left[\frac{B_{0}}{U^{3}} x^{2}+2 \frac{M_{0}}{U^{2}} x\right]+\left(\frac{R_{0}}{\alpha}\right)^{3}\right\}^{1 / 3}-\frac{R_{0}}{\alpha} .
$$

Simplifying Eq. (17) for a buoyant plume with zero source momentum flux, assuming that the effect of buoyancy is dominant and by taking $\alpha=0.6$ (Briggs 1982,1984), we end up with the classical 2/3 power law:

$$
z(x)=1.6 \frac{B_{0}^{1 / 3}}{U} x^{2 / 3}
$$

For cases where there is no mean wind across the plume, i.e., when $U=0$, from the dimensional analysis for a plume with source buoyancy flux $B_{0}$, it can be shown that the rate at which the leading edge of plume rises $w_{f}$ is proportional to $B_{0}^{1 / 3} z_{f}^{-1 / 3}$. Assuming $c_{f}$ to be proportionality constant and using $w_{f}=$ $d z_{f} / d t$, we can integrate this relation to get $z_{f}=\left(3 c_{f} / 4\right)^{3 / 4}$ $B_{0}^{1 / 4} t^{3 / 4}$, where $z_{f}$ is the position of the leading edge or plume rise in this study. This relation between $z_{f}$ and $t$ has been investigated experimentally by Diez et al. (2003), Ai et al. (2006), and Bhamidipati and Woods (2017) and found to be valid for starting plumes. The leading edge of a pure thermal plume rising from a constant heat source also follows the $z_{f} \propto$ $t^{3 / 4}$ relation independent of source buoyancy, as seen from large-eddy simulation study of Bhaganagar and Bhimireddy (2020a) in WRF.

\section{b. Plume penetration}

Similar to $F_{*}$ that tells whether the buoyant plume reaches the CBL top, Richards (1963) and Manins (1979) developed an algorithm to estimate the potential of a buoyant plume to penetrate the boundary layer top. The penetration parameter $f_{p}$ is estimated as follows:

$$
f_{p}=\frac{B_{0} \theta_{a}}{\overline{U g} g \theta_{i} z_{i}^{2}}
$$

where $\Delta \theta_{i}$ is the inversion layer potential temperature jump and $\theta_{a}$ is the ambient air temperature. Depending on the magnitude of $f_{p}$, a buoyant plume released inside a CBL has three possible outcomes: 1 ) no penetration occurs if $f_{p}$ is $<0.03$ (Richards 1963) or $f_{p}<0.06$ (Manins 1979), meaning none of the released plume is strong enough to penetrate the inversion at the top of CBL; 2) full penetration occurs if $f_{p}>0.3$ (Richards 1963), meaning the total plume released inside the CBL will be able to penetrate above the inversion; 3) partial penetration occurs for $0.03<f_{p}<0.3$ (Richards 1963).

\section{Release of ammonia plume in calm air}

In this section, the results of the release of $\mathrm{NH}_{3}$ released in an ideal domain are presented. This serves as the baseline case with no external $\mathrm{ABL}$ forcings such as temperature gradients and wind shear acting on the plume. This will also serve as a validation of the developed model.

The physical problem is as follows: The ambient air is assumed to be idealized and maintained at a constant temperature $\theta_{a}$ with no wind forcing being present. The Coriolis forcing was turned off. $\mathrm{NH}_{3}$ at the same temperature as that of the ambient air was released from a source with a 400-m diameter $D$ located at the ground level with a continuous source flux $Q_{p}$. As the source gas, $\mathrm{NH}_{3}$, was lighter than air, the density difference $\Delta \rho$ with respect to the ambient dry-air density $\rho_{d}$ generated buoyancy. The LES domain had a $4 \mathrm{~km} \times 4 \mathrm{~km} \times$ $7 \mathrm{~km}$ size (i.e., $10 D \times 10 D \times 17.5 D)$ along the two cross-stream (horizontal) and axial (vertical) directions, with the source located at the center of the bottom boundary. The computational domain was discretized using a uniform Cartesian grid with $100 \times 100 \times 700$ nodes in the cross-stream and axial directions. Periodic boundary conditions were imposed on the side boundaries, while a constant pressure boundary condition was imposed on the top. At the center of the bottom boundary, where the source was located, a constant plume surface flux was specified while the remaining bottom boundary had zero flux across. The heat flux boundary condition at the bottom surface was fixed as zero for the entirety of simulation. There was no momentum at the source, so the flow originated purely from the buoyancy difference between the source and the ambient air. The source buoyancy flux $\left(B_{0}=0.25 \pi D^{2} Q_{p} g^{\prime}\right)$ was estimated as $1.07 \times 10^{4} \mathrm{~m}^{4} \mathrm{~s}^{-3}$. 

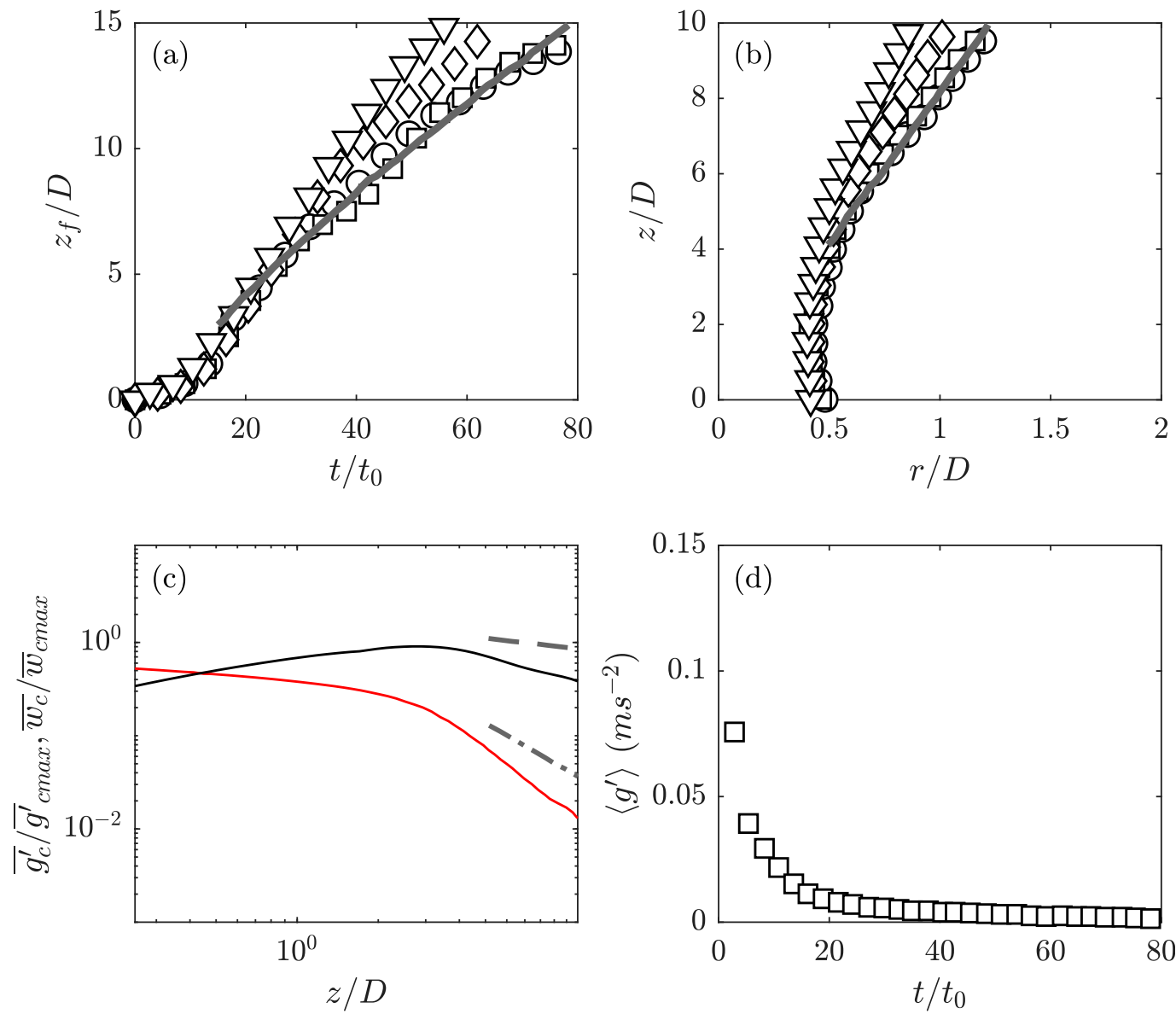

FIG. 1. For Case 1: (a) variation of plume rise $\left(z_{f}\right)$ of a $\mathrm{NH}_{3}$ plume released in neutral background with no winds for grid sizes: $40 \times 40 \times 250$ (inverted triangles), $50 \times 50 \times 350$ (diamonds), $100 \times 100 \times 700$ (squares), and $200 \times$ $200 \times 1400$ (circles); $t_{0}$ is time scale estimated from source diameter $D$ and buoyancy as $t_{0}=\sqrt{D / g_{0}^{\prime}}$. The solid line represents $z_{f} \propto t^{3 / 4}$ trend. (b) Plume radius based on buoyancy profiles for different grid sizes. The solid line represents the growth factor of 0.125 . (c) Variation of normalized mean reduced gravity (red solid line) and normalized mean axial velocity (black solid line) along the centerline of the buoyant plume. The thick dash-dot line represents a $-5 / 3$ slope and dotted line represents a $-1 / 3$ slope. (d) Variation of space averaged $g^{\prime}$. (c),(d) Case 1 with a grid of $100 \times 100 \times 700$.

This source buoyancy flux and the other source conditions that were later used in this study were chosen to be comparable to the real-world scenarios. For example, Lareau and Clements (2017) estimated the source buoyancy flux for 2014 El Portal fire near Yellowstone as $8 \times 10^{4} \mathrm{~m}^{4} \mathrm{~s}^{-3}$ with a 200 -m diameter source. To test the dependency of plume development on the grid size, the $4 \mathrm{~km} \times 4 \mathrm{~km} \times 7 \mathrm{~km}$ domain was discretized with four different grids of equidistantly spaced $40 \times 40 \times 250,50 \times$ $50 \times 350,100 \times 100 \times 700$, and $200 \times 200 \times 1400$ nodes in the horizontal and vertical directions. The source conditions such as the diameter and buoyancy were kept the same for the grid refinement study. A threshold value of $1 \%$ of the source buoyancy was used as the criterion for identifying the plume interface with respect to the ambient air.

\section{a. Plume rise}

The variation of the plume rise with time is given in Fig. 1a. The time was normalized using a time scale $\left(t_{0}=\sqrt{D / g_{0}^{\prime}}\right)$ defined based on initial or source reduced gravity $\left[g_{0}^{\prime}=g\left(\Delta \rho / \rho_{a}\right)\right]$ and source diameter $D$. As the mechanism responsible for the development of starting pure plumes is the buoyancy gradient due to the source, here, $t_{0}$ is considered as the logical time scale for starting plumes in calm ambient air (Diez et al. 2003). After the initial development of the plume head, from after around $20 t_{0}$, the leading edge or plume rise $z_{f}$ varied at a rate of $t^{3 / 4}$ matching with the experimental results obtained by Ai et al. (2006). The timeaveraged buoyancy profiles in the plume were used to quantify the plume radius or plume radial spread.

The variation of the plume radius with respect to the axial location is shown in Fig. 1b. Beyond an axial distance of around $5 D$, the plume radius $r$ increased at a constant rate $(\Delta r / \Delta z)$ of 0.125 , which is comparable to the $0.16 \pm 0.03$ value obtained by Ai et al. (2006) in their starting plume experiments. Recently, Burton et al. (2020) used the WRF Model to simulate buoyant volcanic plumes using a continuous heat source. The variation of the plume width (spread rate in Burton et al. (2020), Fig. 6) 

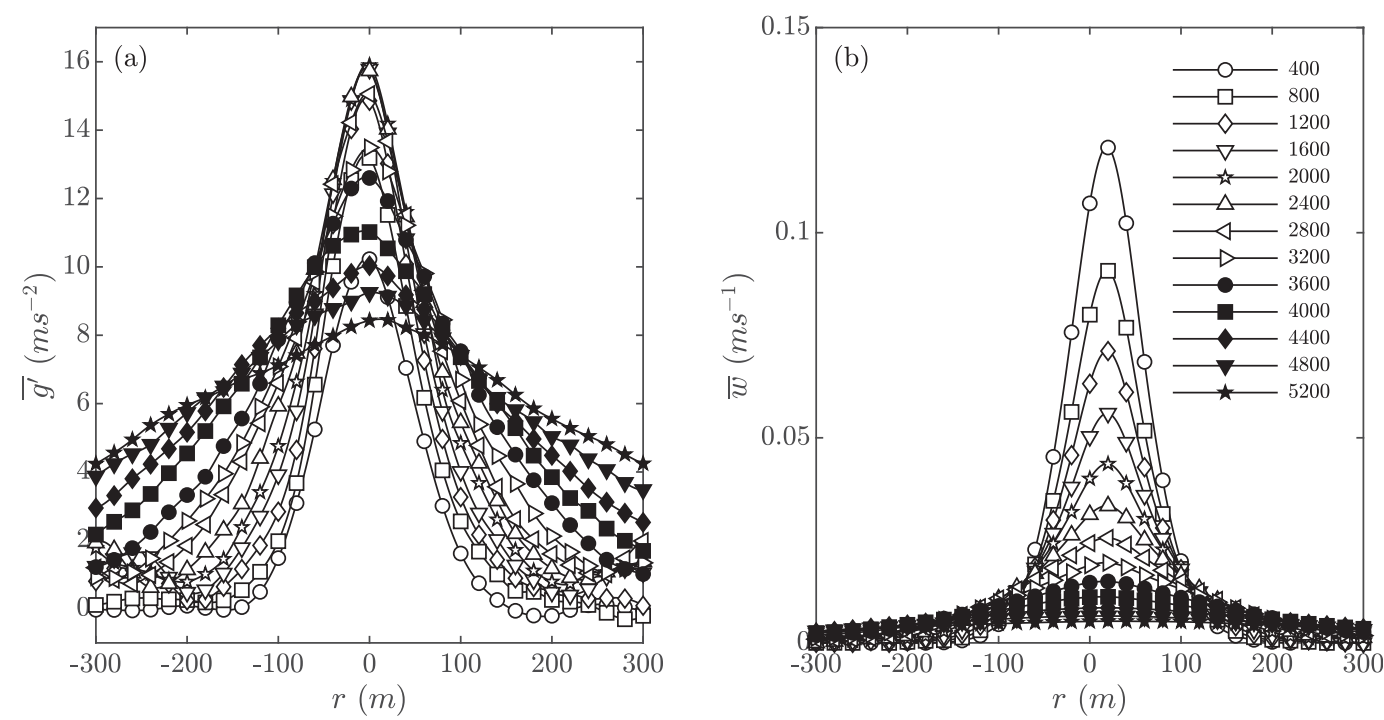

FIG. 2. For Case 1: (a) radial profiles of mean axial velocity of a buoyant plume at different axial locations. The profiles are plotted at an interval of one source diameter $D$ starting from $1 D$ to $10 D$. (b) For mean reduced gravity.

was estimated to be in the range of 0.11 and 0.10 , which closely matches with our results. The results of the plume rise and plume radius variations suggest that grids of $100 \times$ $100 \times 700$ and $200 \times 200 \times 1400$ nodes captured the plume rise and radius development that agree with the existing experimental results. Keeping the computational expense in mind, we chose the grid of $100 \times 100 \times 700$ nodes, i.e., $\Delta x=$ $\Delta y=40 \mathrm{~m}$, for further analysis. Time averaging for velocity and buoyancy was done similar to K. Bhaganagar and S. R. Bhimireddy (2020a). Both the time-averaged axial velocity and buoyancy distributions across the plume cross sections (Figs. 2a,b) exhibited a Gaussian distribution with peak values at the centerline. It should be noted that after the release of buoyant plume, it initially accelerated, reached a maximum value, and was followed by a self-similarity region where it decayed. K. Bhaganagar and S. R. Bhimireddy (2020a), using WRF-LES demonstrated 3/4 power law for plume rise and a linear increase of the plume radius for the buoyant thermal plumes released in the same domain as Case 1. A self-similarity trend was also exhibited by the pure thermal plumes.

\section{b. Plume mixing}

Figure 1c shows the axial variation of the centerline mean velocity and centerline mean buoyancy normalized using their respective maximum centerline values. The maximum mean centerline velocity occurred at a height of $5 D$ above the source and beyond that it decayed with a rate of -0.39 . Similarly, the centerline mean buoyancy decayed with a rate of -1.73 above a height of $5 D$ from the source. Wang and Law (2002) and Ai et al. (2006) conducted experiments on buoyant jets released into quiet ambient air and found out that the centerline velocity and buoyancy decay at a rate of -0.33 and -1.66 , respectively, in the self-similar region, which are comparable to the -0.36 and -1.73 , values obtained in this study.
The plume mixing was analyzed next. The plume mixing and dilution were quantified using instantaneous $g^{\prime}$. For this purpose, the volume-averaged $g^{\prime}$ denoted as $\left\langle g^{\prime}\right\rangle$ is presented in Fig. 1d, which shows its variation with respect to the time. Initially, the plume concentration was high as the head was formed and it started to decay as the ambient fluid mixed with the plume and finally reached a quasi-steady value at about $t / t_{0}=45$.

\section{Release of ammonia plumes in an idealized unstable stratified boundary layer with no winds}

To isolate the effect of atmospheric stratification on the plume dispersion, the $\mathrm{NH}_{3}$ plume was released into an unstable stratified boundary layer with no mean winds. The domain had a $30 D \times 30 D \times 7.75 D$ size for Cases $2-4$ and $20 D \times 20 D \times$ $5.25 \mathrm{D}$ for Case 10 . The $\mathrm{NH}_{3}$ source was located at the center of the bottom boundary. The periodic boundary conditions were used in the lateral direction, and the bottom boundary was specified with a constant heat flux of $0.24 \mathrm{~km} \mathrm{~s}^{-1}$ for Cases 2-4 and $0.50 \mathrm{~km} \mathrm{~s}^{-1}$ for Case 10 . The mean wind was set to $U=$ $0 \mathrm{~m} \mathrm{~s}^{-1}$ for Cases 2-4 and Case 10. The roughness length in the model was set to $0.1 \mathrm{~m}$, and friction velocity estimates were done using the high-frequency output of wind components extracted from WRF Model. The simulations were run for 86400 time steps with a time step of $1 / 6 \mathrm{~s}$. A total of 54000 time steps was spent for the development of a thermal boundary layer. Table 1 gives the details of the cases simulated with unstable stratification and no mean winds, i.e., $U=0 \mathrm{~m} \mathrm{~s}^{-1}$. A total of four cases were simulated with plume source buoyancy fluxes varying from low to high values of $0.58 \times 10^{4}, 1.07 \times 10^{4}$, $2.14 \times 10^{4} \mathrm{~m}^{4} \mathrm{~s}^{-3}$ and $3.52 \times 10^{4} \mathrm{~m}^{4} \mathrm{~s}^{-3}$ corresponding to Cases $2-4$, and Case 10, respectively. The values of the reduced gravity $g^{\prime}$ at the source were $0.043,0.086,0.17$ and $0.28 \mathrm{~m} \mathrm{~s}^{-2}$ for Case 2-4 and Case 10, respectively. 
TABLE 1. Details of cases simulated for $\mathrm{NH}_{3}$ plumes released into atmosphere; $z_{i}$ is the inversion height estimated from temperature and velocity profiles, and $\mathrm{Ri}_{B}$ and $N^{2}$ are the bulk Richardson number and buoyancy frequency estimated at $50 \mathrm{~m}$ from ground. LC17 corresponds to data from 2014 El Portal wildfire near Yosemite National Park (Lareau and Clements 2017).

\begin{tabular}{lcccccccccccccc}
\hline \hline Case & Heat flux & $U$ & $z_{i}$ & $L_{x}$ & $B_{0} \times 10^{4}$ & $\mathrm{Ri}_{B}$ & $N^{2} \times 10^{-4}$ & $L$ & $w_{*}$ & $t_{*}$ & $u_{*}$ & $z_{\text {fmax }} / z_{i}$ & $t_{z i} / t_{*}$ & $f_{p}$ \\
\hline 1 & 0 & 0 & - & - & 1.07 & - & - & - & 0 & - & - & - & - & - \\
2 & 0.24 & 0 & 2100 & 12000 & 0.58 & -2315 & -1.07 & -8.62 & 2.47 & 850 & 0.28 & 1.06 & 1.26 & - \\
3 & 0.24 & 0 & 2100 & 12000 & 1.07 & -2315 & -1.07 & -8.62 & 2.47 & 850 & 0.28 & 1.14 & 0.92 & - \\
4 & 0.24 & 0 & 2100 & 12000 & 2.14 & -2315 & -1.07 & -8.62 & 2.47 & 850 & 0.28 & 1.21 & 0.70 & - \\
5 & 0.24 & 2 & 1180 & 12000 & 3.21 & -4.82 & -1.43 & -1.80 & 2.09 & 565 & 0.178 & 1.43 & 1.06 & 0.048 \\
6 & 0.24 & 2 & 1180 & 12000 & 9.63 & -4.82 & -1.43 & -1.80 & 2.09 & 565 & 0.178 & 1.69 & 0.65 & 0.145 \\
7 & 0.24 & 5 & 1180 & 12000 & 3.21 & -1.31 & -1.52 & -18.39 & 2.09 & 565 & 0.386 & 1.23 & 0.85 & 0.021 \\
8 & 0.24 & 5 & 1180 & 12000 & 1.07 & -1.31 & -1.52 & -18.39 & 2.09 & 565 & 0.386 & 1.15 & 2.11 & 0.0064 \\
9 & 0.24 & 10 & 1180 & 12000 & 3.21 & -0.65 & -8.41 & -82.84 & 2.03 & 616 & 0.636 & 1.19 & 0.81 & 0.0130 \\
10 & 0.50 & 0 & 1250 & 8000 & 3.52 & -5120 & -4.51 & -0.95 & 2.52 & 496 & 0.17 & 1.38 & 0.86 & - \\
11 & 0.50 & 2 & 1250 & 12000 & 3.52 & -21.65 & -14.52 & -0.98 & 2.59 & 483 & 0.184 & 1.35 & 0.58 & 0.0583 \\
12 & 0.50 & 5 & 1250 & 12000 & 3.52 & -3.29 & -15.11 & -7.19 & 2.59 & 483 & 0.359 & 1.20 & 0.92 & 0.0254 \\
13 & 0.50 & 10 & 1250 & 12000 & 3.52 & -0.88 & -15.63 & -28.79 & 2.59 & 483 & 0.572 & 1.06 & 3.88 & 0.0137 \\
LC17 & - & 4.2 & 1424 & - & 8.31 & - & -0.68 & - & 2.45 & 581 & - & 1.93 & - & - \\
\hline
\end{tabular}

\section{a. Characteristics of stratified ABL with no wind forcings}

The boundary layer depth $z_{i}$ was $2100 \mathrm{~m}$ for Cases $2-4$, and $1250 \mathrm{~m}$ for Case 10, respectively. The aspect ratio (i.e., ratio of domain horizontal length $L_{x}$ to the boundary layer height; $\mathrm{AR}=L_{x} / z_{i}$ ) of the model setup considered was $\sim 5.7$ for Cases 2-4 and 6.4 Case 10, which is larger than the minimum required AR of 5 for development of turbulent flow fields in convective boundary layer simulations (Schmidt and Schumann 1989; Sullivan and Patton 2011). The friction velocity and the convective velocity scale were: $u_{*}=0.28 \mathrm{~m} \mathrm{~s}^{-1}, w_{*}=2.47 \mathrm{~m} \mathrm{~s}^{-1}$ for Cases 2-4 and $u_{*}=0.17 \mathrm{~m} \mathrm{~s}^{-1}, w_{*}=2.52 \mathrm{~m} \mathrm{~s}^{-1}$ for Case 10, respectively. The Monin-Obukhov length scale $L$ estimated for Cases 2-4 was $-8.62 \mathrm{~m}$ and for Case 10 was $-0.95 \mathrm{~m}$. The profiles of the mean wind and the potential temperature are shown in Fig. A1 of appendix A. The domain averaged horizontal mean wind inside the domain is $0 \mathrm{~m} \mathrm{~s}^{-1}$. Convective motions in the form of rolls had formed before the plume was released into the ambient air. The temperature jump across the inversion layer was $8 \mathrm{~K}$.

\section{b. Plume rise}

Figures $3 \mathrm{a}$ and $3 \mathrm{~b}$ shows the instantaneous profiles of the plumes with increasing source strength (from left to right in each subplot, Case 2, Case 3, and Case 4) released into the boundary layer, similarly to the pure thermal plumes. As observed by Bhaganagar and Bhimireddy (2020a), plumes consist of a leading front (the head of the plume), followed by a tail region (the stem). The plume develops due to active mixing with the ambient air. The plume rise obtained for all the four cases in this study is given in Fig. 4a. The plume rise variation dependence on time was studied against the power-law fit (dashed line in Fig. 4a). For Cases 2-4, after the initial plume head formation $\left(t / t_{0}<2\right)$, the plume front followed the $t^{3 / 4}$ trend till reaching the boundary layer top $\left(t / t_{0} \sim 12\right)$. The Case 2 plume dissipated quickly and resulted in a puff formation due to the breaking of the plume head from the stem (Fig. 3a). The Case 3 and Case 4 plumes were observed to have accumulated near the boundary layer top and to have spread laterally
(Fig. 3b). The Case 4 plume formed an umbrella-cloud-type structure near the boundary layer as the plume lofts. A similar form of plume accumulation near the boundary layer top was observed in the water tank experiments of Snyder et al. (2002), where the amount of accumulation increased with an increase in source buoyancy. In all the four cases in this study, some portion of the plume crossed $z_{i}$, resulting in $z_{f} / z_{i}>1$. After the plume penetrated the boundary layer, the height of $z_{f}$ settled to a quasi-equilibrium state as it oscillated around its mean value $\overline{z_{f}}$. The scaled maximum height reached by the plume with respect to the CBL depth corresponded to $z_{\text {fmax }} / z_{i}=1.06,1.14,1.21$, and 1.43 for Case 2, Case 3, Case 4, and Case 10, respectively. Ansong and Sutherland (2010) obtained $z_{\text {fmax }} / z_{i}=1.30$ from their tank experiments, when a turbulent buoyant plume of source buoyancy flux of $1.12 \times$ $10^{-6} \mathrm{~m}^{4} \mathrm{~s}^{-3}$ was released into uniform ambient air capped by a stratified layer. They also estimated the $z_{f}$ to reach a quasisteady state value of around $0.9 z_{\text {fmax }}$. For the same boundary layer depth and surface forcing, the scaled maximum height reached by the plume increased from 1.06 to 1.21 with an increase in the source strength from $B_{0}=0.58 \times 10^{4} \mathrm{~m}^{4} \mathrm{~s}^{-3}$ for Case 2 to $B_{0}=2.14 \times 10^{4} \mathrm{~m}^{4} \mathrm{~s}^{-3}$ for Case 4 . This result is consistent with those of the experiments of Morton et al. (1956), where the maximum height reached by a buoyant plume released into stratified ambient air increased with an increase in the source buoyancy flux. Morton et al. (1956) estimated that the maximum height that could be reached by buoyant smoke from a maintained source with a buoyancy flux of $13.5 \mathrm{~m}^{4} \mathrm{~s}^{-3}$ is around $200 \mathrm{~m}$ and that from a source with a buoyancy flux of $7 \times 10^{5} \mathrm{~m}^{4} \mathrm{~s}^{-3}$ is around $3200 \mathrm{~m}$.

Next, we define plume spread $R_{f}$ as the farthest distance traveled by the plume from the source location in the horizontal directions. The variation of plume rise in the axial direction and plume spread in the radial direction are shown in Figs. $4 a$ and $4 b$, respectively. It should be noted that the radial spread of the plume varies approximately linearly with time (Fig. 4b) once the plume front has reached the boundary layer top. For Case 2, close to the source, $z_{f}<2 D$ (i.e., $t / t_{0}<4$ ), the 

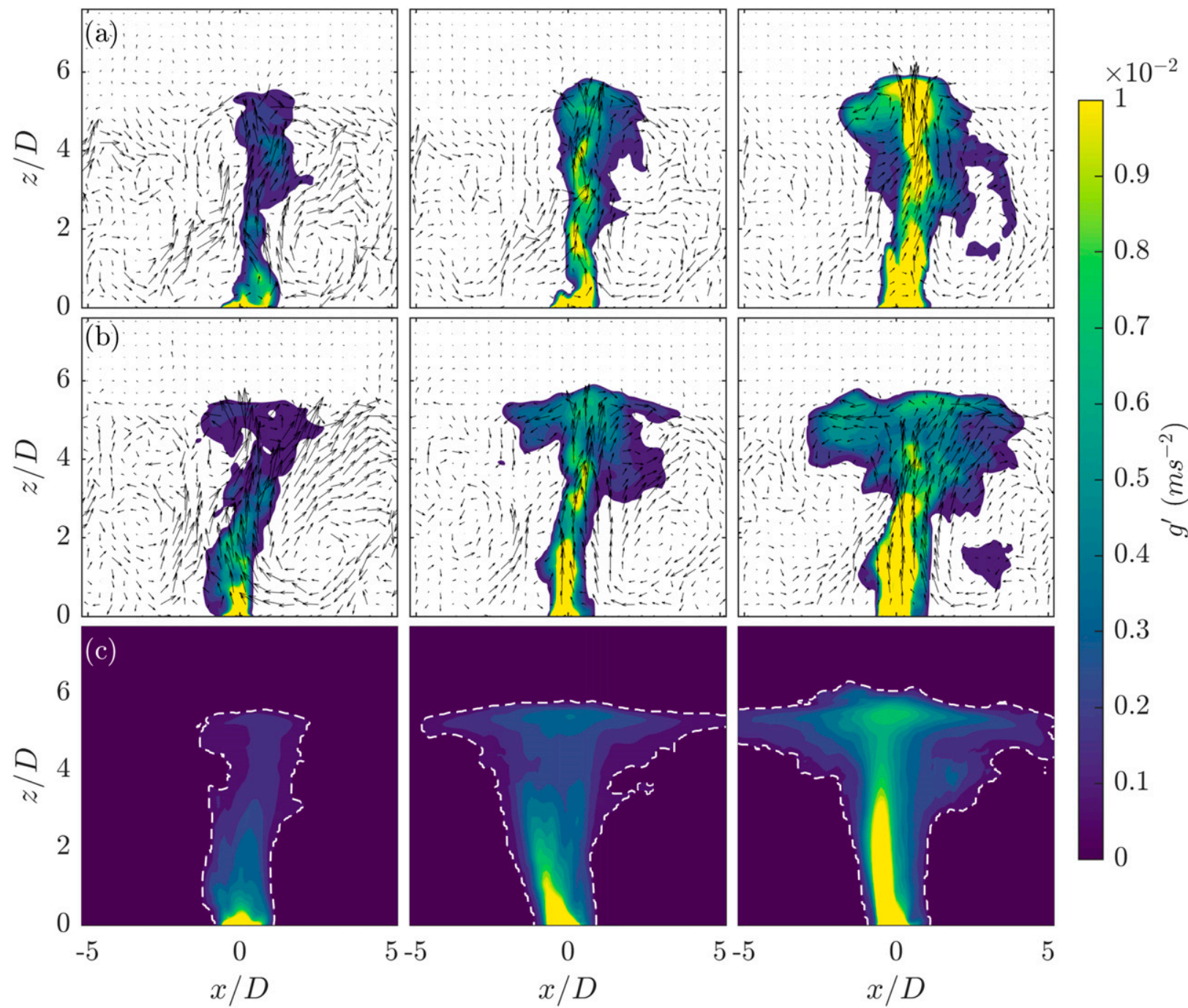

0.7

0.6

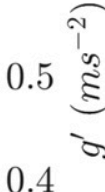

0.4

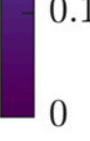

FIG. 3. For Cases 2-4 (left to right): Instantaneous profiles of $\mathrm{NH}_{3}$ plume buoyancy and velocity vectors along the center plane of the domain at (a) $t=1200 \mathrm{~s}$ and (b) $t=2100 \mathrm{~s}$. (c) Contours of time-averaged plume concentration fields. The white dashed line represents the $1 \%$ threshold.

plume spread, $R_{f} \approx 0.5 D$ and when $2 D<z_{f}<5 D$ (i.e., $4<$ $\left.t / t_{0}<11\right), R_{f}$ grew linearly with the height and reached a maximum value of $R_{f}=1.35 \mathrm{D}$, before the further growth of the plume was restricted by the boundary layer top. A similar trend of linear growth of $R_{f}$ was observed at times $3.5<t / t_{0}<11.8$ for Case 3 , and at times $4<t / t_{0}<12.3$ for Case 4 . After the plume reached the boundary layer top, a portion of it impinged and traveled laterally resembling a density current propagation. The rate of spread in the lateral direction was approximately linear as shown by the linear fit line in Fig. 4b. This lateral spreading is similar to the slumping regime of density currents over smooth beds (Rottman and Simpson 1983; Bhaganagar and Pillalamarri 2017).

Due to the presence of convective motions, we can define another time scale using the background atmospheric properties. Following the approach of Briggs (1993), we defined time scale $t_{*}$, as the ratio of the boundary layer depth to the convective velocity $\left(=z_{i} / w_{*}\right.$ ), and we used it to perform time averaging for the cases where the calculation of $t_{*}$ was possible. Here $t_{*}$ is the time taken for one eddy turnover inside the boundary layer. The time that it took the plume front to reach the boundary layer top with respect to $t_{*}$ is given in Table 1 . Time averaging was performed from $t_{*}=2$ to 5 . The contours of the time-averaged buoyancy fields for Case 2-4 are shown in Fig. 3c. The accumulation of the plume near the boundary layer top and the lateral spread is shown in Fig. 3c. The accumulation of buoyant plume at the boundary layer top created a density difference between the plume and the surrounding ambient air at that height, resulting in the lateral spreading of the plume, as seen from the instantaneous plume iso-surface (Fig. 5).

\section{c. Plume mixing}

The plume mixing was analyzed next. Figure $4 \mathrm{c}$ shows $\left\langle g^{\prime}\right\rangle$ plotted versus time nondimensionalized using the buoyant 

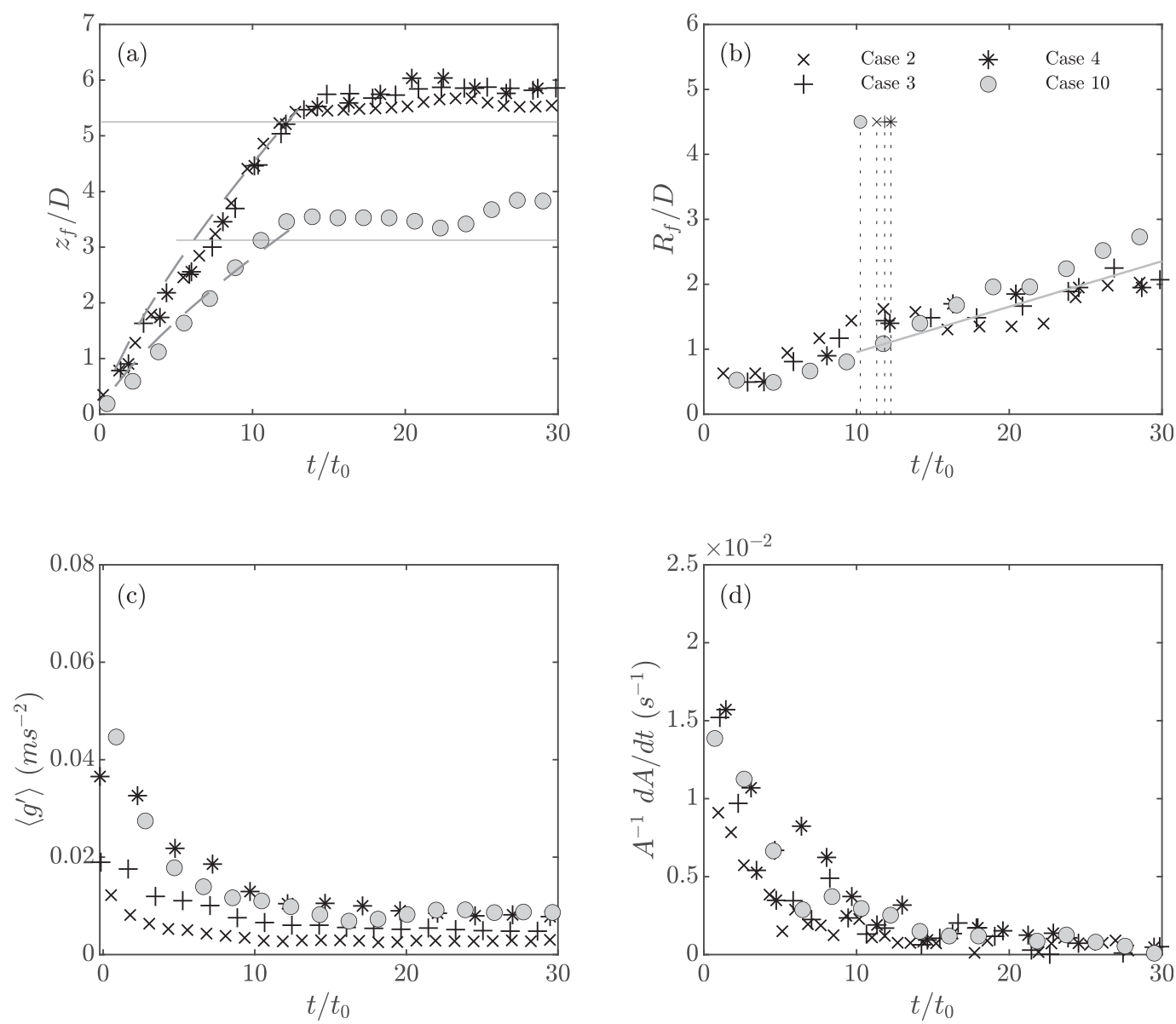

FIG. 4. (a) Variation of plume rise for all three cases simulated in unstable temperature boundary layer. The thin solid lines represent the boundary layer top, and the dashed lines represent $z_{f} \propto t^{3 / 4}$. (b) Variation of plume radial spread for cases simulated in unstable temperature boundary layer. The dash lines represent the respective times when the plume has reached the boundary layer top. The solid line represents the linear trend. (c) Variation of volume averaged reduced gravity. (d) Rate of change of normalized plume area inside boundary layer with respect to nondimensional time $t_{0}$.

time scale $t_{0}$. During the early stages where the plume head was formed, $\left\langle g^{\prime}\right\rangle$ reached its peak value, and after the formation of the head, the mixing with the ambient air was initiated resulting in the decay of $\left\langle g^{\prime}\right\rangle$ until the dilution process reached a quasi-steady-state condition for $t / t_{0}>15$ in Fig. 4c. Comparing Cases 2-4, the time taken for $\left\langle g^{\prime}\right\rangle$ to reach the quasi-steady-state seems to increase with the source buoyancy. In the present study, $\left\langle g^{\prime}\right\rangle$ for Case 2 reached a quasi-steady value $\left(t / t_{0} \sim 10\right)$ much earlier than that of Case $4\left(t / t_{0} \sim 15\right)$. Comparing Case 4 with Case 10, it can be seen that in the initial stages $\left(t / t_{0}<3\right)$, the $\left\langle g^{\prime}\right\rangle$ of Case 10 is higher than Case 4 . This is expected as the source buoyancy is higher in Case 10. At later times, $\left\langle g^{\prime}\right\rangle$ of Case 4 and Case 10 reach a quasi-steady value at approximately same time, which points out that although the plume source buoyancy in Case 10 is higher, it mixes faster than the plume simulated in Case 4. Comparing the $L$ values and the stability parameter $-z_{i} / L$, the faster plume mixing in Case 10 is supported by Case 10 boundary layer being more unstable than Case 4. von Glasow et al. (2003) and Chosson et al. (2008) studied the mixing of buoyant plumes released into a marine CBL from ship exhausts using dilution rate as a metric, which is defined as the normalized rate of change of the plume area. In the present study, the plume area $A$ was estimated based on the plume interface identified by $g^{\prime}$. The rate of change of this plume area, $d A / d t$, treated as dilution, scaled with nondimensional time and reached a quasi-steady value by $t / t_{0}=15$ (Fig. 4d). Chosson et al. (2008) found that the initial source buoyancy flux had a minor impact on the plume mixing after the initial dilution regime or after the first convective eddyturnover cycle.

The presence of an unstable stratified boundary layer restricted the plume rise in the axial direction and the boundary layer top acted as a partial lid. The buoyant plume accumulated near the top of the boundary layer and spreads uniformly in the lateral directions. The higher the source buoyancy flux, the higher the maximum height reached by the plume beyond $z_{i}$. At the inversion layer where the plume growth in the lateral direction scaled linearly resembling the front propagation of a 


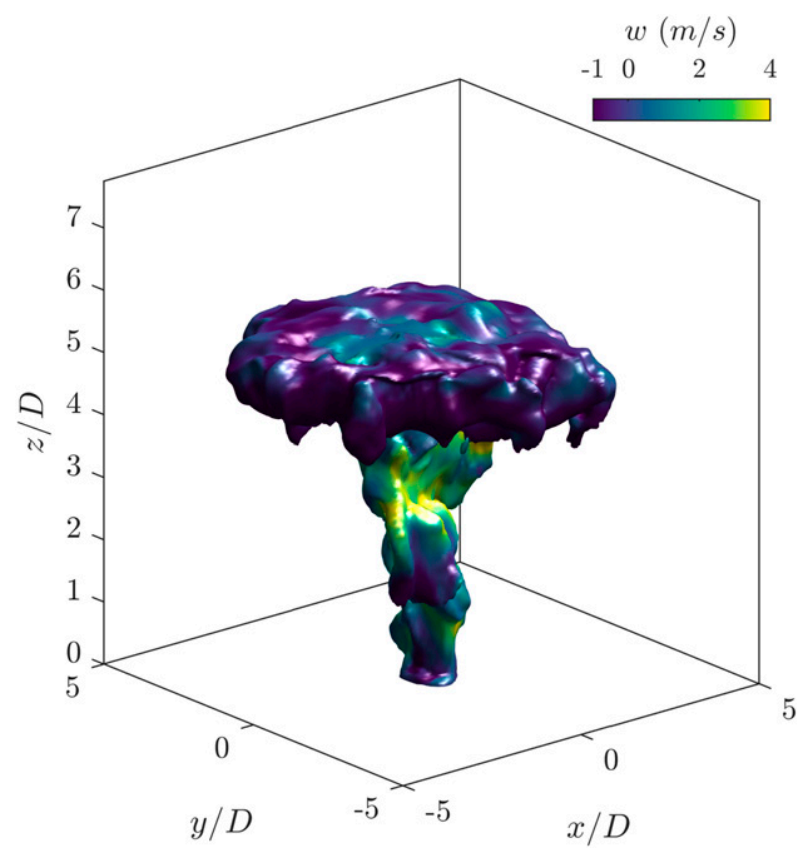

FIG. 5. Instantaneous plume iso-surface for Case 4 after $2300 \mathrm{~s}$ from release. The colors represent the vertical velocity.

density current during the slumping regime. The plume mixing or dilution rate was seen to reach a quasi-steady value. The higher the buoyancy flux, the higher the initial plume concentration at the earlier times, but it eventually reached a quasi-steady state after 15 buoyant time scales.

\section{Release of ammonia plumes in a convective $A B L$}

To understand the combined effects of ambient shear- and temperature- forcing (stratification) on the plume, three different mean winds of low $\left(U=2 \mathrm{~m} \mathrm{~s}^{-1}\right)$, moderate $\left(5 \mathrm{~m} \mathrm{~s}^{-1}\right)$ and high $\left(10 \mathrm{~m} \mathrm{~s}^{-1}\right)$ strengths were used to obtain the background convective boundary layer conditions. $\mathrm{NH}_{3}$ plumes were released into a CBL with a surface heat fluxes of 0.24 (Cases 5-9) and $0.50 \mathrm{~km} \mathrm{~s}^{-1}$ (Cases 11-13). The physical domain had a $30 D \times 20 D \times 6 D$ size and was discretized using $300 \times 200 \times 240$ nodes to keep the grid size the same as before. The aspect ratio for these CBL cases was 9.6 in streamwise and 6.4 in cross-stream directions. The reduced gravity $g^{\prime}$ at the source was $0.25 \mathrm{~m} \mathrm{~s}^{-2}$ for Case 5 , Case 7 and Case 9, and $0.75 \mathrm{~m} \mathrm{~s}^{-2}$ for Case 6 , and $0.086 \mathrm{~m} \mathrm{~s}^{-2}$ for Case 8 , and $0.28 \mathrm{~m} \mathrm{~s}^{-2}$ for Cases 11-13, respectively.

\section{a. CBL characteristics}

The convective scaling parameters for characterizing CBL, including, inversion height $z_{i}$, convective velocity $w_{*}$, bulk Richardson number $\mathrm{Ri}_{B}$, and buoyancy frequency $N^{2}$ are given in Table 1 . The $\mathrm{Ri}_{B}$ and $N^{2}$ were estimated using the wind and temperature fields at the surface level and $50 \mathrm{~m}$ above ground. The temperature jump across the inversion layer at the boundary layer top was around $8 \mathrm{~K}$, and the mixed layer value was $302 \mathrm{~K}$. The stratification aloft had a Brunt-Väisälä
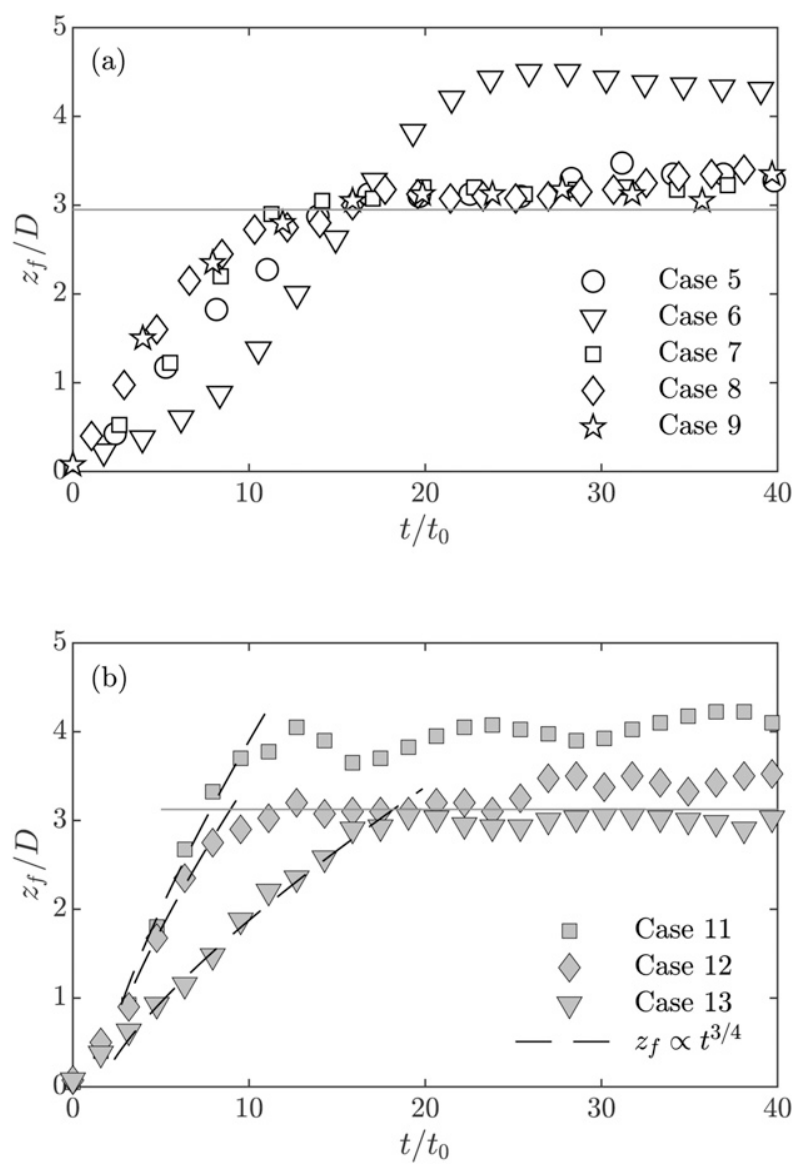

FIG. 6. Variation of plume rise in convective boundary layer for (a) Cases 5-9 and (b) Cases 11-13. The dashed line over each series represents $3 / 4$ power-law variation with time. The thin solid line represents the boundary layer top.

frequency of $N=0.1 \mathrm{~s}^{-1}$. The mean wind speed $\bar{U}$ for Cases 5,6 , and 11 was $1.95 \mathrm{~m} \mathrm{~s}^{-1}$, and that for Cases 7,8 , and 12 was $4.86 \mathrm{~m} \mathrm{~s}^{-1}$, and that for Cases 9 and 13 was $8.83 \mathrm{~m} \mathrm{~s}^{-1}$. The $\mathrm{Ri}_{B}$ and $N^{2}$ were negative, indicating an unstable atmosphere. With $w *$ of $2 \mathrm{~m} \mathrm{~s}^{-1}$ inside a boundary layer depth of $1180 \mathrm{~m}$, the eddy turnover time scale was $565 \mathrm{~s}$ for Cases 5-8. Similarly, the turnover time for Cases 9 was $616 \mathrm{~s}$ and that for Cases 10-13 was $483 \mathrm{~s}$. As the focus of this study was to understand the buoyant plumes from the moment they are released, the analysis was restricted to 5-8 eddy turnover cycles. These values were chosen so as to represent a typical midday over a midlatitude site which has $z_{i}$ around $1000 \mathrm{~m}$, and $w_{*}$ around $2 \mathrm{~m} \mathrm{~s}^{-1}$ (Weil et al. 2002). The values that were considered in this study are comparable to the real world cases such as the 2014 El Portal wildfire near Yosemite National Park, where $z_{i}=1424 \mathrm{~m}, U=4.2 \mathrm{~m} \mathrm{~s}^{-1}$ and $w_{*}=2.45 \mathrm{~m} \mathrm{~s}^{-1}$ (Lareau and Clements 2017).

\section{b. Plume rise}

Figures $6 \mathrm{a}$ and $6 \mathrm{~b}$ shows the variation of the plume rise for Cases 5-8 and Cases 11-13, respectively. Figure 6b shows the effect of the mean wind speed on the plume rise. An increase in 

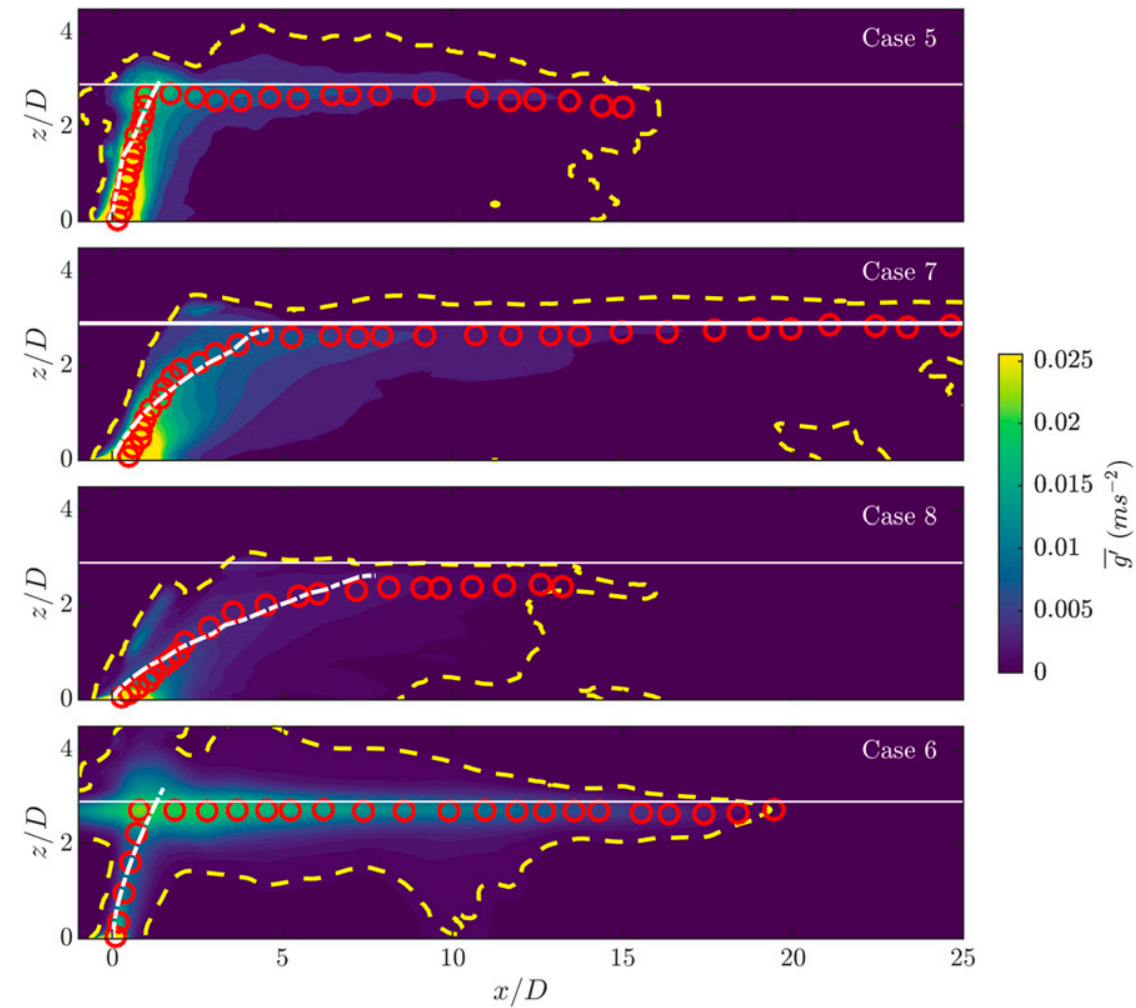

FIG. 7. Mean plume contours with centerline position along the plume for (from top to bottom) Case 5, Case 7, Case 8, and Case 6. The white dash-dot line represents the Plume rise estimated from Briggs formula. The red circles represent the centerline estimated from mean plume contours. The yellow dash line and white solid line in (a) and (b) represent the $1 \%$ threshold plume interface and CBL top, respectively.

the mean wind speed reduced the maximum height reached by the plume. Except for Case 6, all the cases rose to the boundary layer top and loft there. Case 6, which had the highest buoyancy flux of all the cases simulated in this study, penetrated the boundary layer top and continued to rise up about $0.45 z_{i}$ beyond $z_{i}$. The time averaged plume concentration resembled a bent-over plume in crosswinds that lofted or penetrated the boundary layer top (Briggs 1982). The plume centerline was estimated from the plume concentration fields and took the maximum value along each axial position, as shown in Fig. 7. The estimated plume centerline position from the Briggs formula showed a good agreement with the plume centerline obtained from the time-averaged plume concentration fields. The power obtained by fitting each centerline data through a regression is $0.61 \pm 0.02$, which is close to the $2 / 3$ power law in Eq. (18). The variation of $z_{f}$ with respect to time scaled by $t_{*}$ for Cases $5-13$ is shown in Fig. 8.

For the same source buoyancy flux and surface heating, the lateral spread of the plume was greater for Case 7 than for Case 5. The mean wind in CBL for Case 7 was $4.86 \mathrm{~m} \mathrm{~s}^{-1}$, while that for Case 5 was $1.95 \mathrm{~m} \mathrm{~s}^{-1}$. Plume concentration fields shown for Case 5 in Fig. 7 looks qualitatively similar to the buoyant plume dispersion shown in Burton et al. (2020) (see their Fig. 9a) for a background wind shear of $1 \times 10^{-3} \mathrm{~s}^{-1}$. In the present study, the wind shear was estimated using the mean wind at 10 and $200 \mathrm{~m}$. For Case 5 and Case 11 the wind shear was $1.4 \times$ $10^{-3} \mathrm{~s}^{-1}$, for Case 7 and Case 12 was $7 \times 10^{-3} \mathrm{~s}^{-1}$, and for Case 8 and Case 13 it was $1.5 \times 10^{-2} \mathrm{~s}^{-1}$. The effect of increased wind shear is seen in the near-source concentration fields for Case 5 and Case 7 as shown in Fig. 7. The mean concentration field of Case 6 as seen from Fig. 7, revealed interesting features of plume trapping above the boundary layer. Also observed was the lateral spread of the plume against the mean wind near the boundary layer top. In the absence of any mean wind, the impinging plume spread uniformly whereas in the presence of mean wind inside the CBL, the balance between the upward buoyancy force and lateral mean winds resulted in a nonuniform lateral spread, as seen in Case 6 (Fig. 7). Due to a strong buoyancy flux at the source, the plume in Case 6 moved up resulting in a very low ground concentration for a downwind distance of $x<5 D$ from the source. Averaged over multiple eddy turnover cycles, the plume that was aloft was brought down close to the ground at higher downwind distances $(x>5 D)$.

\section{c. Plume penetration of the $C B L$}

The penetration parameter estimated for all the cases simulated in this study are given in Table 1 . Due to lack of existing 


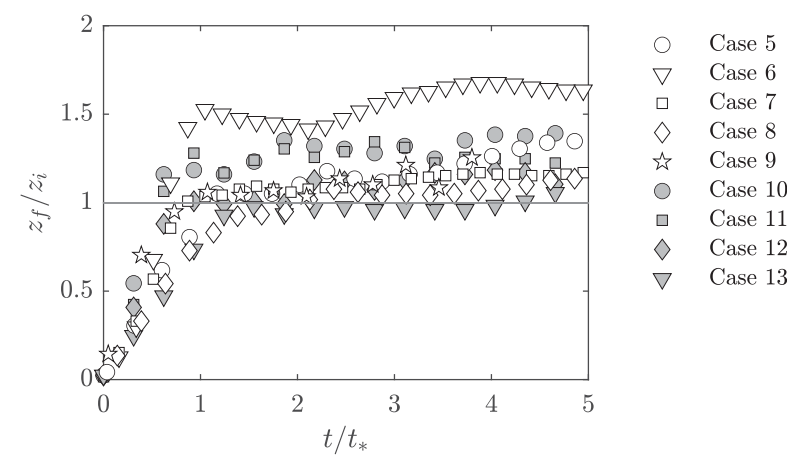

FIG. 8. Variation of plume rise normalized by CBL depth with respect to nondimensional time for Case 5 -Case 13; here, $t *$ is the convective time scale.

parameterization for estimating $f_{p}$ in case of zero wind cases, we restricted the penetration analysis to cases where a mean wind is present across the domain (Cases 5-9 and Cases 12-13 in this study).

Among the cases that were simulated, the highest penetration factor was that for Case 6 with $f_{p}=0.145$, which is greater than the no-penetration criteria, making the plume more likely to penetrate CBL as seen in Figs. 6a and 7. The lowest penetration factor for the cases with a nonzero mean wind was obtained for Case 8 , with $f_{p}=0.0064$. Cases 5, 6, and 11 had $f_{p}$ values of $0.048,0.145$, and 0.0583 , respectively, which are greater than Richards's (1963) criterion for no penetration. Cases 7 and 12 had $f_{p}$ values of 0.021 and 0.0254 , which are close to the limiting criterion of Richards (1963). To quantify the CBL penetration by buoyant plume, the average plume concentration that reached a value above the inversion layer height was evaluated. Overall, $24.31 \%$ of the total plume that was released into the domain had penetrated the inversion layer for Case 6 . The percentages of plume that penetrated the inversion height for remaining cases, in descending order, were: $11.81 \%$ for Case 5, 6.77\% for Case 7, 5.83\% for Case 11, $2.54 \%$ for Case $12,1.37 \%$ for Case $13,1.36 \%$ for Case 8 and $1.3 \%$ for Case 9 . Comparing Case 5 and Case 7, the increase in wind shear near the source seems to have reduced the amount of plume penetrating the CBL top. The same can be said for Cases 11-13, where the percentage plume penetrated the CBL reduced from $5.83 \%$ to $1.37 \%$ with an increase in shear from $1.4 \times 10^{-3}$ to $1.5 \times 10^{-2} \mathrm{~s}^{-1}$. The percentage of plume penetrated the CBL top was seen to increase with an increase in $f_{p}$ and the variation of this amount with respect to the $f_{p}$ is shown in Fig. 9a. The accurate prediction of this value is important, as often regulatory transport and dispersion models such as AERMOD often uses an additional source to represent this penetrated plume.

As discussed in the previous section and as shown in Fig. 9b, the plume rise $z_{f}$ after penetrating the CBL top reached the maximum height and beyond which it settled at a quasi-steady height $\overline{z_{f}}$. The amount of plume that penetrated the CBL inversion was correlated with the $\overline{z_{f}}$ as shown in Fig. 9b, where $\overline{q_{p}} \%$ varies linearly with $\overline{z_{f}} / z_{i}$ with a slope of 40 and an $R^{2}$ value of 0.98 .
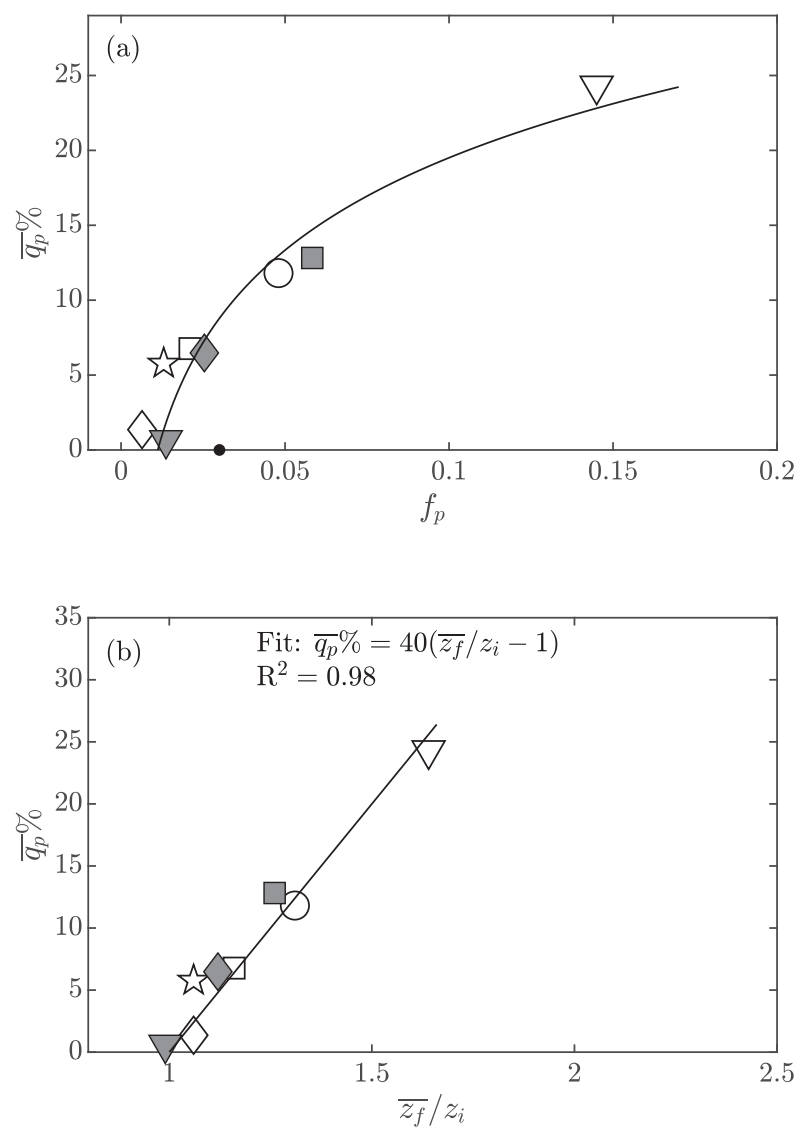

FIG. 9. Percentage of total plume penetrated the CBL top against the penetration parameter. The black dot on the $x$ axis represents the Richards (1963) cutoff criterion for plume penetration. Symbols represent cases given in Fig. 8.

\section{d. Plume mixing}

The mixing characteristics of the released plumes will be discussed next. As seen in Fig. 10a, soon after the release of the $\mathrm{NH}_{3}$ plume, the overall concentration increased sharply before diluting due to the active mixing of the plume inside CBL. The rate of change of the space-averaged buoyancy with respect to $t / t_{*}$ scaled to power law with a $-3 / 2$ coefficient as shown in Fig. 10c. As the plume mixed with the ambient air, it expanded in size. The rate of change of the normalized surface area occupied by the plume followed a power law which had a similar coefficient as $d\left\langle g^{\prime}\right\rangle / d t$, as seen in Fig. 10b. The rate of change of $\left\langle g^{\prime}\right\rangle$ does not scale with time scale $t_{0}$ based on buoyancy velocity and source diameter (Fig. 10d). This result demonstrates that the mixing of buoyant plume in a CBL scales with the CBL time scales $t_{*}$ and not with the buoyancy scaling of the plume.

To understand the vertical distribution of plume within the CBL, the area-integrated concentration $\hat{g}^{\prime}$ at each height and time step was obtained. The profiles of $\hat{g}^{\prime}$ for Cases $9-10$ and 12-13 at four different times from time of release are shown in Fig. 11. For Cases 5 and 7, the amount of plume released was distributed inside the CBL with some of it accumulating for Case 5, while most of the plume resembled a mixed profile for 

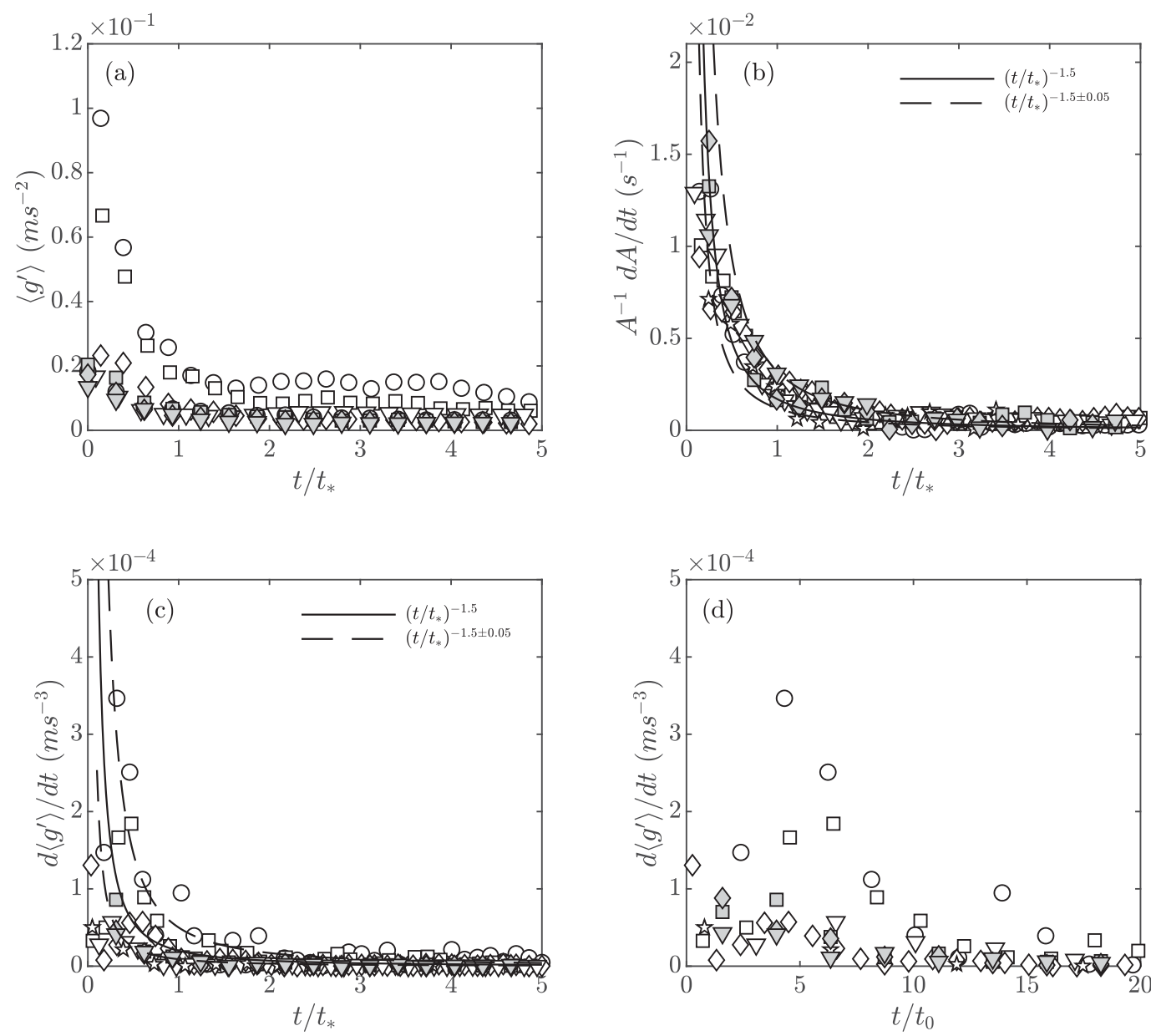

FIG. 10. (a) Variation of mean plume concentration inside the CBL. (b) Rate of change of normalized plume area inside CBL with respect to nondimensional time. (c) Rate of change of mean concentration inside CBL with respect to nondimensional time based on convective time scale. (d) Rate of change of mean concentration inside CBL with respect to nondimensional time based on buoyant time scale.

Case 7. Interestingly for Case 6, the amount of plume near the CBL top was orders of magnitude higher than the amount of plume that was present closer to the ground. For Case 8 , the source strength was weaker than that of Cases $5-7$, and as a result the plume concentration profiles had a smaller magnitude, and they were restricted to below the CBL depth. Knowing the height distribution of plume is critical for dispersion modeling as often modelers use a single plume injection height derived empirically to release tracers or emissions.

It is likely useful for dispersion modelers to know the vertical distribution of the concentration at relative distances to the source, so that the profiles can be used to initialize the transport and dispersion models instead of using a single injection height which is the common practice. Thus, the crosswind and time-averaged plume concentration $\left\langle g^{\prime}\right\rangle_{y}$ profiles were investigated at distances relative to the source and were defined in terms of the source diameter. We have included the downwind distance, $x$, made dimensionless using convective scaling, $X=w_{*} x /\left(U z_{i}\right)$ (Deardorff and Willis 1975) in the Fig. 11 legend. Time averaging was conducted for $1<t / t_{*}=5$. The resulting profiles at downwind distances of $x / D=1,3,5$ and 7 normalized with the maximum value at $x / D=1$ and are plotted in Figs. 12a and 12b for Cases 9-10 and Cases 12-13. The comparison of Figs. 12a and 12b, revealed that the effect of the mean winds was dominant along the downwind distances. The maximum concentration at $x / D=1$ in Case 9 was located on the ground surface $\left(z / z_{i}=0\right)$, whereas the maximum concentration for Case 10 was located close to the boundary layer top $\left(z / z_{i}=1\right)$. For $x / D>1$, the profiles were well mixed by $x / D=5$ for Case 9 , while Case 10 profiles have maximum values near the boundary layer top. The comparison of Figs. 12c and $12 \mathrm{~d}$, revealed that the effect of the mean wind could be seen in nonuniform mixing of plume profiles in Case 12 at $x / D=7$, whereas the profiles at $x / D=7$ for Case 13 were well mixed.

The presence of mean wind aids in mixing the plume within the CBL resulting in uniformly mixed plume profiles. For a given boundary layer height, surface heat forcing and source buoyancy, an increase in mean wind enhances the plume 

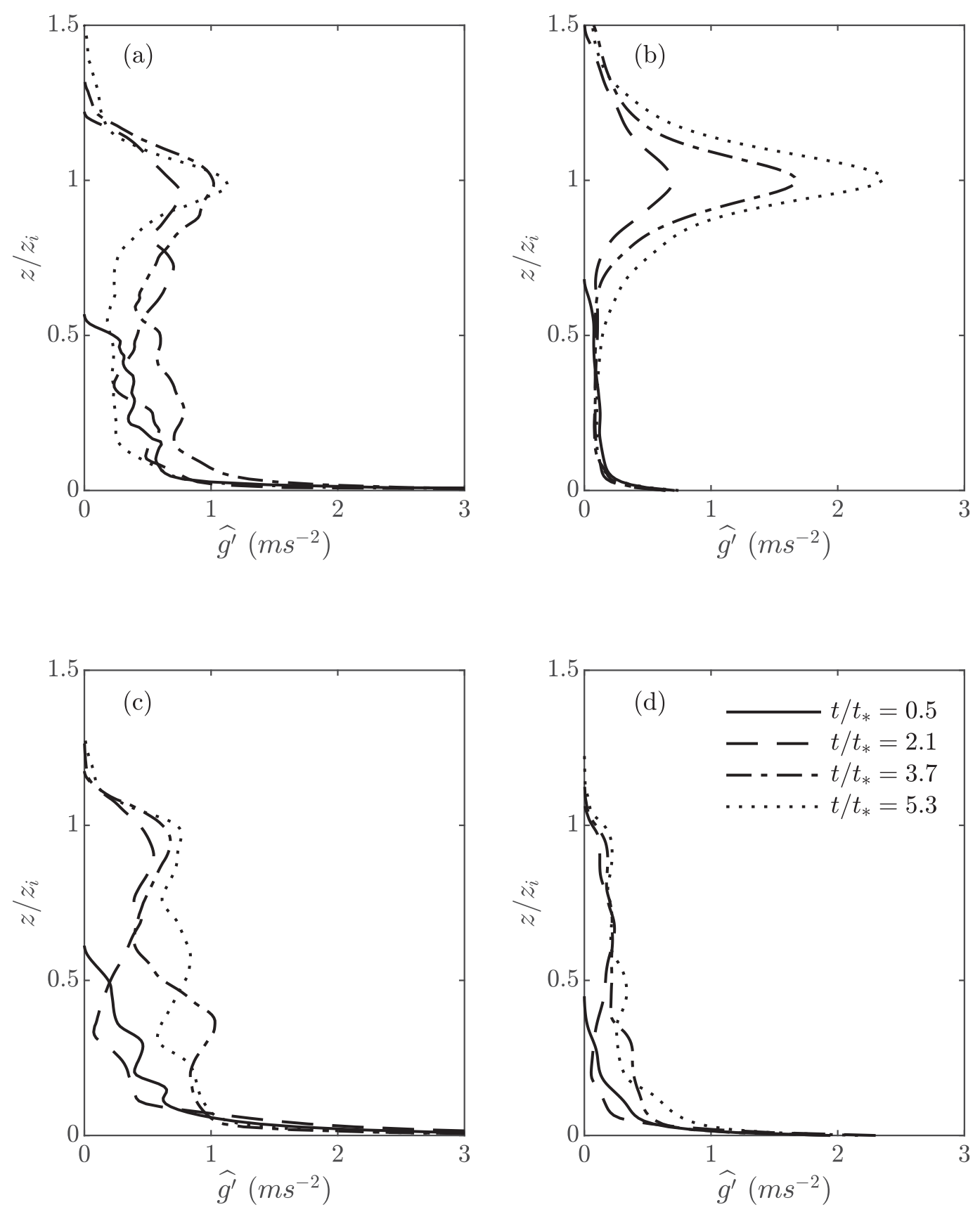

FIG. 11. Instantaneous profiles of (horizontal) area integrated plume concentration for (a) Case 5, (b) Case 6,

(c) Case 7, and (d) Case 8 at four different times from plume release scaled using the convective time scale.

mixing resulting in faster dilutions during the early plume development.

\section{Summary}

A new LES formulation for buoyant plumes has been developed within WRF for the first time to represent the dynamic interaction between the ambient atmospheric boundary layer and the buoyant plumes. The dynamic interactions between the atmospheric forcing and the buoyant plumes (e.g., the interactions between the atmospheric turbulent updrafts and downdrafts with the plume) that cause the plume dispersion have been represented by coupling the WRF formulations with an additional advection-diffusion equation and with a new gas mixture equation. In addition, the additional turbulence kinetic energy production due to buoyancy forcings of the plume has been added to the subgrid-scale TKE equation within WRF. The classical WRF-LES has only the capability to 

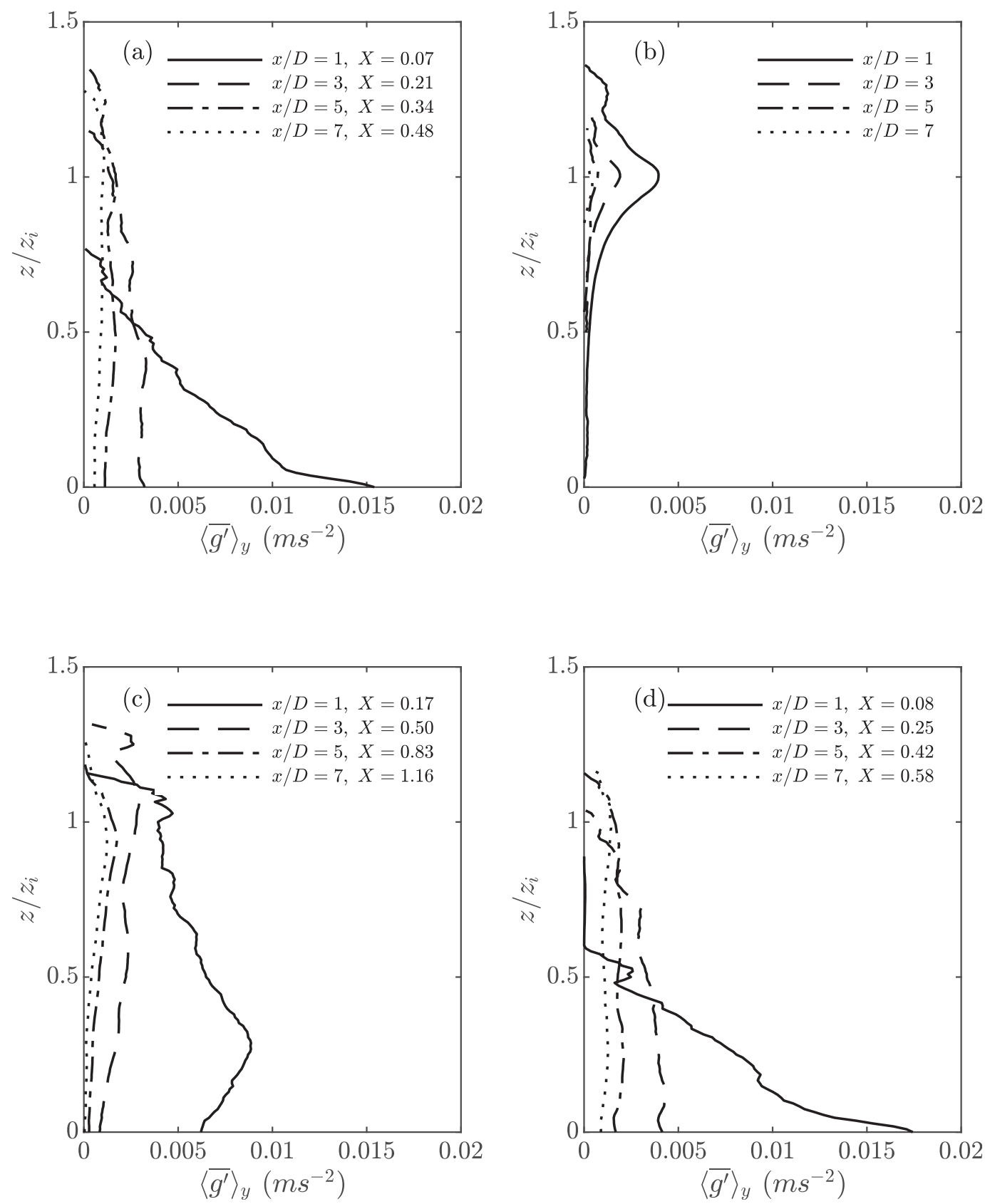

FIG. 12. Variation of crosswind mean plume concentration inside the CBL at different downwind distances for (a) Case 9, (b) Case 10, (c) Case 12, and (d) Case 13. The convective dimensionless distance $X=w * x /\left(U z_{i}\right)$ is added in the legend for cases with $U \neq 0 \mathrm{~m} \mathrm{~s}^{-1}$.

simulate passive plumes. The main disadvantage with that approach is that only thermal plumes (with the same gas constant as the ambient) can be simulated, and further the TKE production is underestimated as the TKE production due to the plume buoyancy forcings cannot be accounted for. To address these limitations, a major shift in paradigm has been achieved with the new formulation. The bPlume-WRF-LES formulation accounts for buoyancy forcings due to differences in the temperature between the ambiance and plume, and also due to differences in the gas constant values. Hence, the formulation can be used to simulate chemical plumes (e.g., $\mathrm{NH}_{3}$, $\mathrm{He}, \mathrm{CO}$ ) within the WRF framework as the plume dispersion, plume mixing and plume entrainment processes are represented accurately. This is a novel addition to the WRF-LES model to simulate chemical plumes such as smoke plumes and wildland fire plumes with different emission gases.

To demonstrate the efficacy of the new formulation, the release of $\mathrm{NH} 3$ plumes into the atmosphere has been studied. 

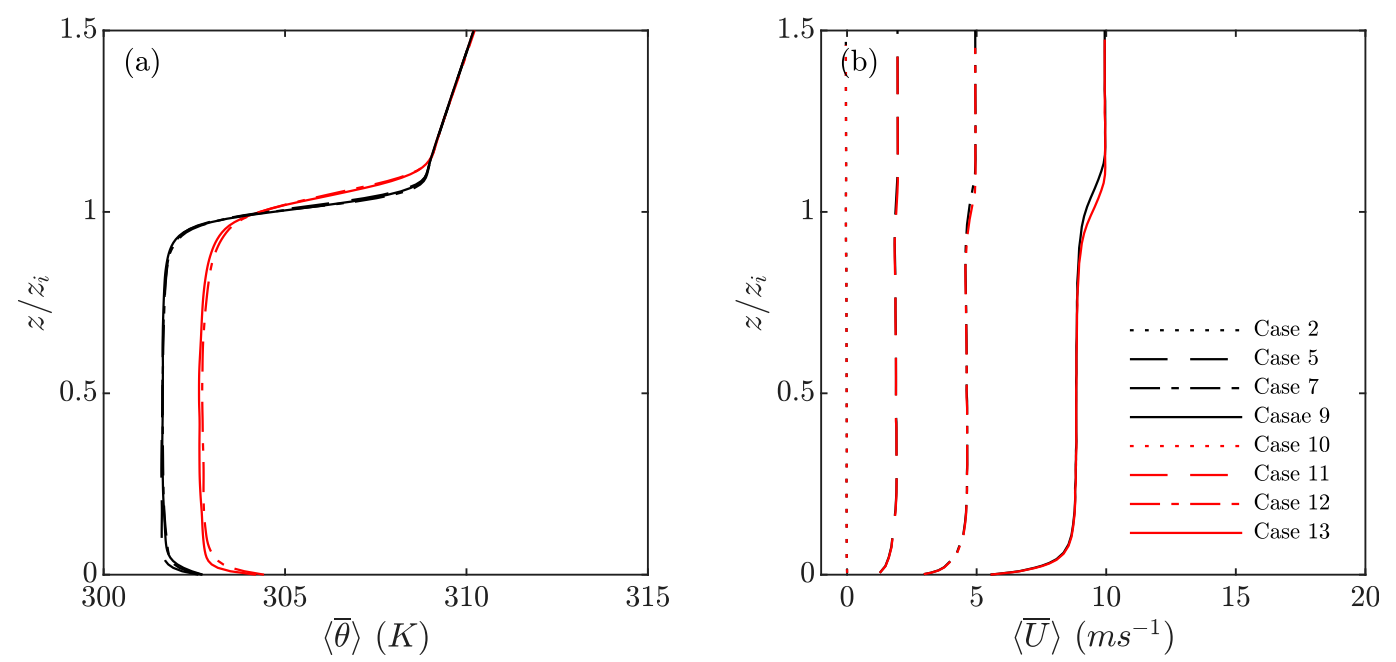

FIG. A1. Domain- and time-averaged mean (a) potential temperature and (b) velocity profiles.

The new bPlume-WRF-LES model was used to understand the release of ammonia $\left(\mathrm{NH}_{3}\right)$ plumes from a large-area source into different atmospheric conditions for number of case$\mathrm{s}$-including quiet air with no temperature gradient (treated as a base-line case); stratified thermal boundary layer with no winds and moderate and high surface heat flux forcing, and a CBL with weak, moderate, and strong mean winds and moderate and high surface heat flux forcings.

For the $\mathrm{NH}_{3}$ plume released into quiet ambient air without any stratification or winds, the plume rise varied at a rate of $3 / 4$ power law with time as expected. The mean radial distribution of velocity and buoyancy profiles were Gaussian with the maximum values at the centerline, and decaying along the axial direction. For $\mathrm{NH}_{3}$ plumes released into a stratified thermal boundary layer with no winds, the vertical growth of the plume was restricted by the presence of a thermal boundary layer and an umbrella cloud type distribution of plume was also observed as the plume starts spreading in lateral direction at the boundary layer top. The rate of lateral spread showed a linear trend with time, resembling a front propagation of a density current over smooth bed in its slumping phase. For $\mathrm{NH}_{3}$ plumes released into convective boundary layer, the plume rise growth was proportional to $t^{2 / 3}$. The plume rise for very strong buoyancy source in weak winds was almost vertical with very little deformation to mean winds inside the boundary layer. The buoyant centerline for $\mathrm{NH}_{3}$ plumes released in $\mathrm{CBL}$ well matched with Briggs formula (Briggs 1982) for bent-over plumes.

The penetration parameter $f_{p}$ based on the background atmospheric stability and the source buoyancy flux of $\mathrm{NH}_{3}$ plumes is the basis of determining whether the plume penetrates the CBL or not. An increase in $f_{p}$ resulted in a greater amount of plume penetrating the CBL. The total amount of plume that penetrated the CBL scaled linearly with the final mean plume rise above the CBL. Although there is no parameterization for $f_{p}$ in zero wind scenarios in this study, a significant amount of plume was seen penetrating the boundary layer highlighting the need for penetration model development for zero wind cases.
This study demonstrated the convective time $t_{*}$ based on the convective velocity and CBL top as the scaling parameter for the plumes in CBL. The mixing and dilution rate of plumes scales as $t_{*}^{-3 / 2}$ power law. The amount of plume mixing increases for the $\mathrm{NH}_{3}$ plumes released in a stratified boundary layer compared to those release in an unstratified and quiet atmosphere. The presence of mean wind in a stratified boundary layer, further enhances plume mixing for a given boundary and surface heat forcing. An increase in mean wind forcing enhances the plume mixing resulting in faster plume dilution as the plume develops. The profile variations of areaintegrated plume concentration offer insight for dispersion modelers to use vertical distribution of plume/emissions rather than a single injection height. Even after multiple convective eddy cycles had passed, the plumes released in the weak and moderate mean wind cases were not well mixed. Further, plumes generated from a strong source buoyancy flux released in CBL with weak winds have higher concentrations at the CBL top as the plume within the CBL mixes. The time-averaged plume concentration profiles showed uniform mixing within $\mathrm{CBL}$ in case of the presence of strong winds for both weak and moderate surface heat forcing. For a given surface heat forcing and source buoyancy, an increase in mean winds inside the CBL will result in uniform mixing at shorter downwind distances.

Overall, this study contributed much to the extension of the WRF-LES formulation to account for the dynamic interactions between the buoyant forcings of the plume and the atmospheric boundary layer. The key contributions of the research presented here are twofold: First, the development of the new formulation within WRF-LES has resulted in a major shift in the computational paradigm of simulating buoyant plumes within WRF. Only passive thermal air plumes, with the same gas constant of the plume as that of the ambient atmosphere, can be simulated with the existing WRF formulation. However, the new formulation introduces a capability to represent the dynamic interactions between the gas plumes (both dense and lighter gas) and the surrounding ABL. 

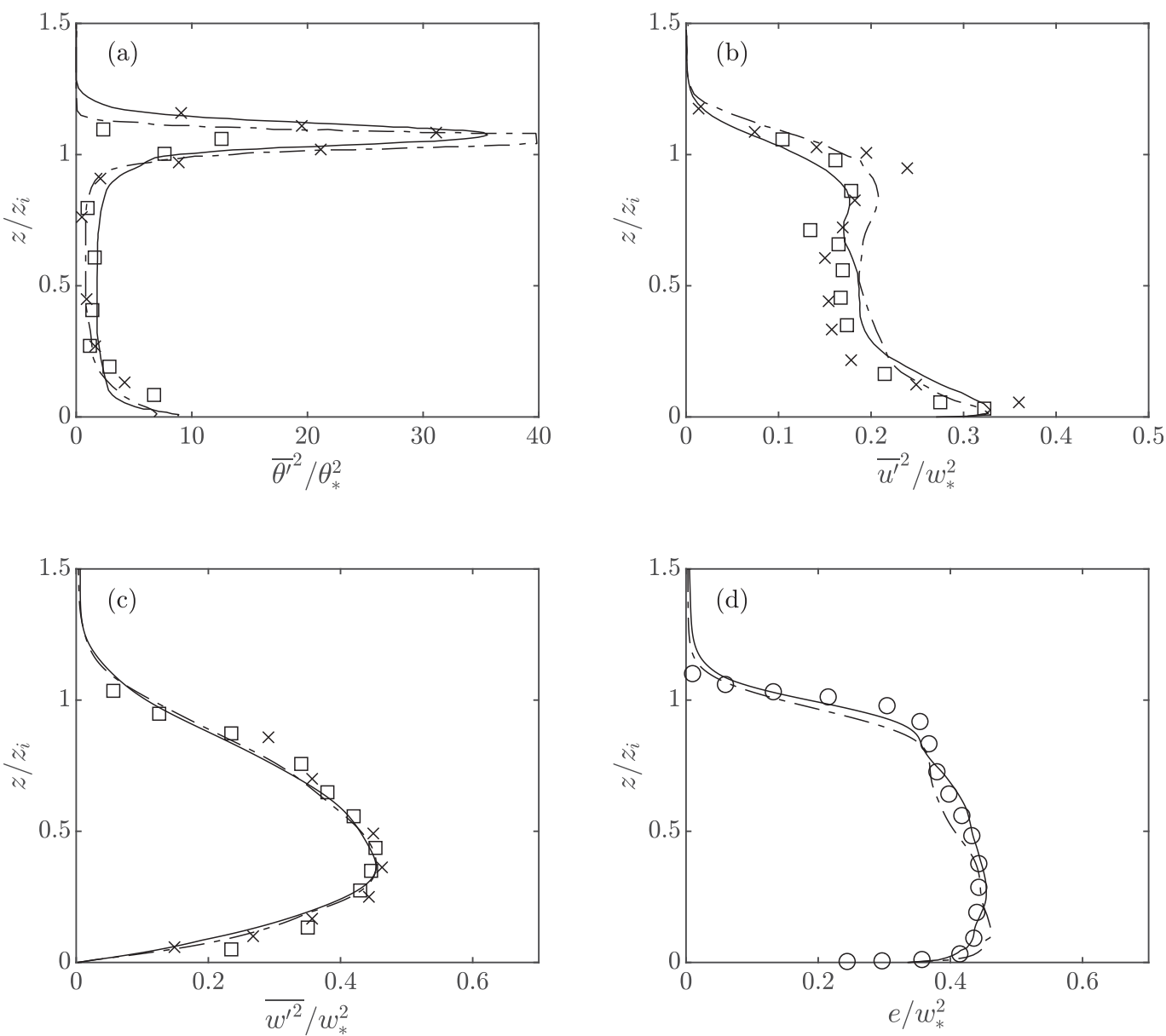

FIG. A2. Vertical profiles of (a) temperature variance normalized by potential temperature scale, (b) resolved velocity variance, $(\mathrm{c})$ vertical velocity variance, and (d) TKE variation with height. The solid line in each subfigure represents Case 9, while the dash-dot line represents Case 12. White squares represent Willis and Deardorff (1976) channel data, crosses represent Raasch and Etling (1991) data, and circles indicate data from LES of Sullivan and Patton (2011).

Second, the scaling laws for the plume height, plume width, and plume penetration factors for different background atmospheric stratification conditions, and for different plume buoyancy forcings, have been obtained and validated with the existing theoretical findings. Further, new scaling laws for plume mixing have been derived. Another important consequence of the proposed work is that due to the dynamic representation of the atmospheric turbulence with the plume turbulence in the new formulation of WRF-LES, the study has important implications in the existing numerical methods for determining plume characteristics. In particular, plume dispersion is highly variable in a convective ABL due to strong updrafts and downdrafts that lead to substantial plume meandering. LES is a reliable method for studying the statistical variability in dispersion by using long-time-averaged mean characteristics (Wyngaard 1984). An alternate approach commonly used is the Lagrangian approach using LES velocity fields to drive the particle dispersion (e.g., Weil et al. 2012). In their study, the ensemble is built by modeling the particle trajectories and dispersion from each of 30 widely separated sources at a given height in the ABL to create 30 "independent" realizations each approximating a 30-min averaging period. The underlying assumption is that each of the ensembles represents a different location of the release of the source with respect to the updrafts and downdrafts. The plume behavior when released into an updraft or the downdraft is different. e.g., the centerline descent will represent with higher probability the instances the plume is released into the downdraft. Hence, by using an ensemble of realizations, the time-averaged plume characteristics are realized through the ensemble averaging. However, there are various limitations to this approach. It does not account for the modifications in the updrafts/downdrafts due to the plumegenerated turbulence and assumes passive plumes. The new bPlume-WRF-LES formulation addresses these limitations: Due to the two-way feedback between the ABL and the plume, the interactions between the atmospheric turbulent updrafts and downdrafts with the plume-generated turbulence are dynamic, and the long-time-averaged statistics realize the plume characteristics to a high degree of accuracy. This obviates the 
need to conduct an ensemble averaging to account for the variability due to plume meandering, e.g., varying the source location with respect to the updrafts. Further, as the locations of the updrafts/downdrafts vary in time, it is not possible to know a priori their location with respect to the source, as the plume disperses over time. Further, for strong plumes such as wildland fires, the fire plumes develop their meteorology resulting in plume-generated turbulent updrafts and downdrafts that interact with the atmospheric turbulence. The bPlume-WRF-LES has the numerical capability to represent weak to strong plumes in different atmospheric boundary layer conditions.

Acknowledgments. The authors would like to acknowledge Texas Advanced Computing Center (TACC) for computational support. The authors would like to acknowledge the support staff at National Center for Atmospheric Research (NCAR) for their technical support with questions during model implementation. Funding for the study was obtained from NASA Center for Advanced Measurements in Extreme Environments, Grant 80NSSC19M0194.

\section{APPENDIX A}

\section{Boundary Layer Characteristics for Cases Simulated}

Figure A1 shows the domain and time-averaged mean profiles of wind and potential temperature for the cases simulated. Time averaging was done over five eddy turnover cycles before releasing the plumes to calculate the ABL profiles. Figure A2 shows normalized vertical profiles of temperature variance, horizontal and vertical velocity variances and TKE for Case 9 and Case 12. Data from experiments of Willis and Deardorff (1976) and LES of Raasch and Etling (1991) are used to compare the variances calculated. LES data of Sullivan and Patton (2011) is used to compare the TKE profiles. The maximum vertical velocity variance occurred at around $0.4 z_{i}$. Overall, the variance profiles are in good agreement with experimental and numerical data from other LES codes.

\section{APPENDIX B}

\section{Nomenclature}

1) Monin-Obukhov length scale L (Monin and Obukhov 1954)

$$
L=-\frac{\rho_{a} c_{p} u_{*}^{3} T_{\mathrm{ref}}}{\kappa g H},
$$

where $\rho, c_{p}, T_{\text {ref }}$ are density, specific heat of air, and reference temperature, respectively; $g$ is the gravitational constant; $u_{*}$ is the friction velocity; $\kappa$ is the von Karman constant (typically $=0.41$ ); and $H$ is the surface kinematic heat flux.

2) Convective velocity scale $w *$

$$
w_{*}=\left(\frac{g}{T_{a}} z_{i} \overline{w^{\prime} \theta_{v_{s}}^{\prime}}\right)^{1 / 3},
$$

where $w_{*}$ is the Deardorff (or convective) velocity, $T_{a}$ is the ambient absolute temperature, $z_{i}$ is the depth of the convective boundary layer (CBL), and $\overline{w^{\prime} \theta_{v_{s}}^{\prime}}$ is the kinematic heat flux at the surface flux.

3) Bulk Richardson number $\mathrm{Ri}_{B}$

$$
\mathrm{Ri}_{B}=\frac{g \Delta \theta_{v} \Delta z}{\theta_{v} \Delta \bar{U}^{2}},
$$

where $\Delta \theta_{v}$ and $\Delta \bar{U}$ are differences in virtual potential temperature and mean wind speed across a layer of $\Delta z$ thickness.

$B_{0} \quad$ Source buoyancy flux $\left(\mathrm{m}^{4} \mathrm{~s}^{-3}\right)$

$F_{*} \quad$ Nondimensional buoyancy flux parameter

$f_{p} \quad$ Penetration factor

$g^{\prime} \quad$ Reduced gravity, plume concentration $\left(\mathrm{m} \mathrm{s}^{-2}\right)$

$R_{f} \quad$ Radial spread of plume with respect to source (m)

$t_{0} \quad$ Time scale based on reduced gravity at source (s)

$t * \quad$ Time scale based on convective velocity and boundary layer depth (s)

$\bar{U} \quad$ Mean wind inside $\mathrm{ABL}\left(\mathrm{m} \mathrm{s}^{-1}\right)$

$z_{i} \quad$ Boundary layer depth (m)

$z_{f} \quad$ Plume rise height from source $(\mathrm{m})$

$z_{\text {fmax }}$ Maximum plume rise height $(\mathrm{m})$

$\overline{z_{f}} \quad$ Mean plume rise height $(\mathrm{m})$

$\left\langle g^{\prime}\right\rangle \quad$ Space averaged in $x, y$, and $z\left(\mathrm{~m} \mathrm{~s}^{-2}\right)$

$\left\langle g^{\prime}\right\rangle_{y} \quad$ Space averaged in $y\left(\mathrm{~m} \mathrm{~s}^{-2}\right)$

$\left\langle\overline{g^{\prime}}\right\rangle \quad$ Space averaged in $x, y, z$ and time averaged $\left(\mathrm{m} \mathrm{s}^{-2}\right)$

$\widehat{g^{\prime}} \quad$ Area-integrated plume concentration at each height $\left(\mathrm{m} \mathrm{s}^{-2}\right)$

\section{REFERENCES}

Adams, C., and Coauthors, 2019: Satellite-derived emissions of carbon monoxide, ammonia, and nitrogen dioxide from the 2016 Horse River wildfire in the Fort McMurray area. Atmos. Chem. Phys., 19, 2577-2599, https://doi.org/10.5194/acp-192577-2019.

Ai, J., A. W.-K. Law, and S. Yu, 2006: On Boussinesq and nonBoussinesq starting forced plumes. J. Fluid Mech., 558, 357386, https://doi.org/10.1017/S0022112006000061.

Andreae, M. O., 2019: Emission of trace gases and aerosols from biomass burning-An updated assessment. Atmos. Chem. Phys., 19, 8523-8546, https://doi.org/10.5194/acp19-8523-2019.

Ansong, J. K., and B. R. Sutherland, 2010: Internal gravity waves generated by convective plumes. J. Fluid Mech., 648, 405-434, https://doi.org/10.1017/S0022112009993193.

Bannon, P. R., 2002: Theoretical foundations for models of moist convection. J. Atmos. Sci., 59, 1967-1982, https://doi.org/ 10.1175/1520-0469(2002)059<1967:TFFMOM>2.0.CO;2.

Bhaganagar, K., and S. R. Bhimireddy, 2017: Assessment of the plume dispersion due to chemical attack on April 4, 2017, in Syria. Nat. Hazards, 88, 1893-1901, https://doi.org/10.1007/ s11069-017-2936-x.

—_, and N. R. Pillalamarri, 2017: Lock-exchange release density currents over three-dimensional regular roughness elements. J. Fluid Mech., 832, 793-824, https://doi.org/ 10.1017/jfm.2017.678.

_- , and S. R. Bhimireddy, 2020a: Local atmospheric factors that enhance air-borne dispersion of coronavirus-highfidelity numerical simulation of COVID19 case study in 
real-time. Environ. Res., 191, 110170, https://doi.org/ 10.1016/j.envres.2020.110170.

$\longrightarrow$, and $-2020 \mathrm{~b}$ : Numerical investigation of starting turbulent buoyant plumes released in neutral atmosphere. J. Fluid Mech., 900, A32, https://doi.org/10.1017/jfm.2020.474.

Bhamidipati, N., and A. W. Woods, 2017: On the dynamics of starting plumes. J. Fluid Mech., 833, R2, https://doi.org/ 10.1017/jfm.2017.762.

Bhimireddy, S. R., and K. Bhaganagar, 2018a: Performance assessment of dynamic downscaling of WRF to simulate convective conditions during sagebrush phase 1 tracer experiments. Atmosphere, 9, 505, https://doi.org/10.3390/ atmos 9120505.

$\longrightarrow$, and — 2018b: Short-term passive tracer plume dispersion in convective boundary layer using a high-resolution WRFARW model. Atmos. Pollut. Res., 9, 901-911, https://doi.org/ 10.1016/j.apr.2018.02.010.

Bierly, E. W., and E. W. Hewson, 1962: Some restrictive meteorological conditions to be considered in the design of stacks. J. Appl. Meteor., 1, 383-390, https://doi.org/10.1175/15200450(1962)001<0383:SRMCTB > 2.0.CO;2.

Bowman, D. M., and F. H. Johnston, 2005: Wildfire smoke, fire management, and human health. EcoHealth, 2, 76-80, https:// doi.org/10.1007/s10393-004-0149-8.

Bowne, N., and R. Londergan, 1983: Overview, results, and conclusions for the EPRI plume-model validation and development project: Plains site. TRC Environmental Consultants Tech. Rep. EPRI-EA-3074, 230 pp.

Briggs, G. A., 1965: A plume rise model compared with observations. J. Air Pollut. Control Assoc., 15, 433-438, https://doi.org/ 10.1080/00022470.1965.10468404.

_ 1982: Plume rise predictions. Lectures on Air Pollution and Environmental Impact Analyses, D. Haugen, Ed., Springer, 59-111.

_ 1984: Plume rise and buoyancy effects. Atmospheric Science and Power Production, D. Randerson, Ed., U.S. Department of Energy, https://doi.org/10.2172/6503687.

_- 1993: Plume dispersion in the convective boundary layer. Part II: Analyses of condors field experiment data. J. Appl. Meteor., 32, 1388-1425, https://doi.org/10.1175/ 1520-0450(1993)032<1388:PDITCB > 2.0.CO;2.

Bryan, G. H., and J. M. Fritsch, 2002: A benchmark simulation for moist nonhydrostatic numerical models. Mon. Wea. Rev., 130, 2917-2928, https://doi.org/10.1175/1520-0493(2002)130<2917: ABSFMN $>2.0 . \mathrm{CO} ; 2$.

Burton, R., J. Dudhia, A. Gadian, and S. Mobbs, 2017: The use of a numerical weather prediction model to simulate the release of a dense gas with an application to the Lake Nyos disaster of 1986. Meteor. Appl., 24, 43-51, https://doi.org/ 10.1002/met.1603.

— M. J. Woodhouse, A. M. Gadian, and S. D. Mobbs, 2020: The use of a numerical weather prediction model to simulate nearfield volcanic plumes. Atmosphere, 11, 594, https://doi.org/ 10.3390/atmos11060594.

Chosson, F., R. Paoli, and B. Cuenot, 2008: Ship plume dispersion rates in convective boundary layers for chemistry models. Atmos. Chem. Phys., 8, 4841-4853, https://doi.org/10.5194/ acp-8-4841-2008.

Cimorelli, A. J., and Coauthors, 2005: AERMOD: A dispersion model for industrial source applications. Part I: General model formulation and boundary layer characterization. J. Appl. Meteor., 44, 682-693, https://doi.org/10.1175/ JAM2227.1.
Coen, J. L., M. Cameron, J. Michalakes, E. G. Patton, P. J. Riggan, and K. M. Yedinak, 2013: WRF-Fire: Coupled weatherwildland fire modeling with the Weather Research and Forecasting Model. J. Appl. Meteor. Climatol., 52, 16-38, https://doi.org/10.1175/JAMC-D-12-023.1.

Deardorff, J., 1970: Convective velocity and temperature scales for the unstable planetary boundary layer and for Rayleigh convection. J. Atmos. Sci., 27, 1211-1213, https://doi.org/10.1175/ 1520-0469(1970)027<1211:CVATSF >2.0.CO;2.

_ and G. Willis, 1975: A parameterization of diffusion into the mixed layer. J. Appl. Meteor., 14, 1451-1458, https://doi.org/ 10.1175/1520-0450(1975)014<1451:APODIT>2.0.CO;2.

Diez, F., R. Sangras, G. Faeth, and O. Kwon, 2003: Self-preserving properties of unsteady round buoyant turbulent plumes and thermals in still fluids. J. Heat Transfer, 125, 821-830, https:// doi.org/10.1115/1.1597620.

Dolgin, E., 2013: Syrian Gas Attack Reinforces Need for Better Anti-Sarin Drugs. Nature Med., 19, 1194-1195.

Golder, D., 1972: Relations among stability parameters in the surface layer. Bound.-Layer Meteor., 3, 47-58, https://doi.org/ 10.1007/BF00769106.

Grell, G. A., S. E. Peckham, R. Schmitz, S. A. McKeen, G. Frost, W. C. Skamarock, and B. Eder, 2005: Fully coupled "online" chemistry within the WRF model. Atmos. Environ., 39, 69576975, https://doi.org/10.1016/j.atmosenv.2005.04.027.

Holtslag, A. A., and F. T. Nieuwstadt, 1986: Scaling the atmospheric boundary layer. Bound.-Layer Meteor., 36, 201-209, https://doi.org/10.1007/BF00117468.

Kaimal, J., J. Wyngaard, D. Haugen, O. Coté, Y. Izumi, S. Caughey, and C. Readings, 1976: Turbulence structure in the convective boundary layer. J. Atmos. Sci., 33, 2152-2169, https://doi.org/ 10.1175/1520-0469(1976)033<2152:TSITCB > 2.0.CO;2.

Khan, F., S. Rathnayaka, and S. Ahmed, 2015: Methods and models in process safety and risk management: Past, present and future. Process Saf. Environ. Prot., 98, 116-147, https:// doi.org/10.1016/j.psep.2015.07.005.

Kim, S.-W., S.-U. Park, and C.-H. Moeng, 2003: Entrainment processes in the convective boundary layer with varying wind shear. Bound.-Layer Meteor., 108, 221-245, https://doi.org/ 10.1023/A:1024170229293.

Kling, G. W., and Coauthors, 1987: The 1986 Lake Nyos gas disaster in Cameroon, West Africa. Science, 236, 169-175, https://doi.org/10.1126/science.236.4798.169.

Kochanski, A. K., M. A. Jenkins, K. Yedinak, J. Mandel, J. Beezley, and B. Lamb, 2016: Toward an integrated system for fire, smoke and air quality simulations. Int. J. Wildland Fire, 25, 534-546, https://doi.org/10.1071/WF14074.

Lareau, N. P., and C. B. Clements, 2017: The mean and turbulent properties of a wildfire convective plume. J. Appl. Meteor. Climatol., 56, 2289-2299, https://doi.org/10.1175/JAMC-D-160384.1.

Leelőssy, Á., F. Molnár, F. Izsák, Á. Havasi, I. Lagzi, and R. Mészáros, 2014: Dispersion modeling of air pollutants in the atmosphere: A review. Cent. Eur. J. Geosci., 6, 257-278, https://doi.org/10.2478/s13533-012-0188-6.

Lutsch, E., E. Dammers, S. Conway, and K. Strong, 2016: Longrange transport of $\mathrm{NH}_{3}, \mathrm{CO}, \mathrm{HCN}$, and $\mathrm{C}_{2} \mathrm{H}_{6}$ from the 2014 Canadian Wildfires. Geophys. Res. Lett., 43, 8286-8297, https://doi.org/10.1002/2016GL070114.

_ - and Coauthors, 2019: Unprecedented atmospheric ammonia concentrations detected in the high Arctic from the 2017 Canadian Wildfires. J. Geophys. Res. Atmos., 124, 8178-8202, https://doi.org/10.1029/2019JD030419. 
Mandel, J., and Coauthors, 2014: Recent advances and applications of WRF-SFire. Nat. Hazards Earth Syst. Sci., 14, 2829-2845, https://doi.org/10.5194/nhess-14-2829-2014.

Manins, P., 1979: Partial penetration of an elevated inversion layer by chimney plumes. Atmos. Environ., 13, 733-741, https:// doi.org/10.1016/0004-6981(79)90203-8.

Michalakes, J., J. Dudhia, D. Gill, T. Henderson, J. Klemp, W. Skamarock, and W. Wang, 2005: The Weather Research and Forecast Model: Software architecture and performance. Use of High Performance Computing in Meteorology, W. Zwieflhofer, Ed.,World Scientific, 156-168.

Moeng, C.-H., and P. P. Sullivan, 1994: A comparison of shear-and buoyancy-driven planetary boundary layer flows. J. Atmos. Sci., 51, 999-1022, https://doi.org/10.1175/1520-0469(1994) $051<0999$ :ACOSAB $>2.0 . \mathrm{CO} ; 2$.

Monin, A. S., and A. M. Obukhov, 1954: Basic laws of turbulent mixing in the surface layer of the atmosphere. Tr. Akad. Nauk USSR Geophiz. Inst., 24 (151), 163-187.

Morton, B., 1957: Buoyant plumes in a moist atmosphere. J. Fluid Mech., 2, 127-144, https://doi.org/10.1017/S0022112057000038.

—_, G. I. Taylor, and J. S. Turner, 1956: Turbulent gravitational convection from maintained and instantaneous sources. Proc. Roy. Soc. London, 234A, 1-23, https:// doi.org/10.1098/rspa.1956.0011.

Murray, D., and N. Bowne, 1988: Urban power plant plume studies. Electric Power Research Institute Rep. EA-5468, Research Project 2736-1, 236 pp.

Nottrott, A., J. Kleissl, and R. Keeling, 2014: Modeling passive scalar dispersion in the atmospheric boundary layer with WRF large-eddy simulation. Atmos. Environ., 82, 172-182, https:// doi.org/10.1016/j.atmosenv.2013.10.026.

Nunalee, C. G., B. Kosović, and P. E. Bieringer, 2014: Eulerian dispersion modeling with WRF-LES of plume impingement in neutrally and stably stratified turbulent boundary layers. Atmos. Environ., 99, 571-581, https://doi.org/10.1016/ j.atmosenv.2014.09.070.

Oberhuber, J. M., M. Herzog, H.-F. Graf, and K. Schwanke, 1998: Volcanic plume simulation on large scales. J. Volcanol. Geotherm. Res., 87, 29-53, https://doi.org/10.1016/S03770273(98)00099-7.

Panofsky, H. A., H. Tennekes, D. H. Lenschow, and J. Wyngaard, 1977: The characteristics of turbulent velocity components in the surface layer under convective conditions. Bound.-Layer Meteor., 11, 355-361, https://doi.org/10.1007/ BF02186086.

Pasquill, F., 1961: The estimation of the dispersion of windborne material. Meteor. Mag., 90, 33-40.

Powers, J. G., and Coauthors, 2017: The Weather Research and Forecasting Model: Overview, system efforts, and future directions. Bull. Amer. Meteor. Soc., 98, 1717-1737, https:// doi.org/10.1175/BAMS-D-15-00308.1.

Raasch, S., and D. Etling, 1991: Numerical simulation of rotating turbulent thermal convection. Contrib. Atmos. Phys., 64, 185199.

Reid, C. E., M. Brauer, F. H. Johnston, M. Jerrett, J. R. Balmes, and C. T. Elliott, 2016: Critical review of health impacts of wildfire smoke exposure. Environ. Health Perspect., 124, 1334-1343, https://doi.org/10.1289/ehp.1409277.

Richards, J., 1963: The penetration of interfaces by cylindrical thermals. Quart. J. Roy. Meteor. Soc., 89, 254-264, https:// doi.org/10.1002/qj.49708938006.

Rottman, J. W., and J. E. Simpson, 1983: Gravity currents produced by instantaneous releases of a heavy fluid in a rectan- gular channel. J. Fluid Mech., 135, 95-110, https://doi.org/ 10.1017/S0022112083002979.

Salesky, S. T., M. Chamecki, and E. Bou-Zeid, 2017: On the nature of the transition between roll and cellular organization in the convective boundary layer. Bound.-Layer Meteor., 163, 41-68, https://doi.org/10.1007/s10546-016-0220-3.

Schmidt, H., and U. Schumann, 1989: Coherent structure of the convective boundary layer derived from large-eddy simulations. J. Fluid Mech., 200, 511-562, https://doi.org/10.1017/ S0022112089000753.

Skamarock, W. C., J. B. Klemp, J. Dudhia, D. O. Gill, D. M. Barker, W. Wang, and J. G. Powers, 2005: A description of the Advanced Research WRF version 2. NCAR Tech. Note NCAR/TN-468+STR, 88 pp., http://doi.org/10.5065/ D6DZ069T.

Sklavounos, S., and F. Rigas, 2006: Estimation of safety distances in the vicinity of fuel gas pipelines. J. Loss Prev. Process Ind., 19, 24-31, https://doi.org/10.1016/j.jlp.2005.05.002.

Slawson, P., and G. Csanady, 1967: On the mean path of buoyant, bent-over chimney plumes. J. Fluid Mech., 28, 311-322, https:// doi.org/10.1017/S0022112067002095.

Snyder, W. H., R. E. Lawson, M. S. Shipman, and J. Lu, 2002: Fluid modelling of atmospheric dispersion in the convective boundary layer. Bound.-Layer Meteor., 102, 335-366, https:// doi.org/10.1023/A:1013857632438.

Stein, A., R. R. Draxler, G. D. Rolph, B. J. Stunder, M. Cohen, and F. Ngan, 2015: NOAA's HYSPLIT atmospheric transport and dispersion modeling system. Bull. Amer. Meteor. Soc., 96, 2059-2077, https://doi.org/10.1175/BAMS-D-14-00110.1.

Stohl, A., C. Forster, A. Frank, P. Seibert, and G. Wotawa, 2005: The Lagrangian particle dispersion model flexpart version 6.2. Atmos. Chem. Phys., 5, 2461-2474, https://doi.org/10.5194/ acp-5-2461-2005.

Sullivan, P. P., and E. G. Patton, 2011: The effect of mesh resolution on convective boundary layer statistics and structures generated by large-eddy simulation. J. Atmos. Sci., 68, 23952415, https://doi.org/10.1175/JAS-D-10-05010.1.

Trentmann, J., and Coauthors, 2006: Modeling of biomass smoke injection into the lower stratosphere by a large forest fire (Part I): Reference simulation. Atmos. Chem. Phys., 6, 52475260, https://doi.org/10.5194/acp-6-5247-2006.

Van Dop, H., 1992: Buoyant plume rise in a Lagrangian framework. Atmos. Environ., 26A, 1335-1346, https://doi.org/10.1016/09601686(92)90394-Z.

Van Ulden, A., and A. Holtslag, 1985: Estimation of atmospheric boundary layer parameters for diffusion applications. J. Climate Appl. Meteor., 24, 1196-1207, https://doi.org/10.1175/15200450(1985)024<1196:EOABLP>2.0.CO;2.

von Glasow, R., M. G. Lawrence, R. Sander, and P. J. Crutzen, 2003: Modeling the chemical effects of ship exhaust in the cloud-free marine boundary layer. Atmos. Chem. Phys., 3, 233-250, https://doi.org/10.5194/acp-3-233-2003.

Wang, H., and A. W. Law, 2002: Second-order integral model for a round turbulent buoyant jet. J. Fluid Mech., 459, 397-428, https://doi.org/10.1017/S0022112002008157.

Weil, J. C., L. Corio, and R. Brower, 1997: A PDF dispersion model for buoyant plumes in the convective boundary layer. J. Appl. Meteor., 36, 982-1003, https://doi.org/10.1175/1520-0450(1997) 036<0982:APDMFB $>2.0 . \mathrm{CO} ; 2$.

- W. H. Snyder, R. E. Lawson, and M. S. Shipman, 2002: Experiments on buoyant plume dispersion in a laboratory convection tank. Bound.-Layer Meteor., 102, 367-414, https:// doi.org/10.1023/A:1013874816509. 
_ , P. P. Sullivan, E. G. Patton, and C.-H. Moeng, 2012: Statistical variability of dispersion in the convective boundary layer: Ensembles of simulations and observations. Bound.-Layer Meteor., 145, 185-210, https://doi.org/10.1007/s10546-012-9704-y.

Willis, G., and J. Deardorff, 1976: A laboratory model of diffusion into the convective planetary boundary layer. Quart. J. Roy. Meteor. Soc., 102, 427-445, https://doi.org/10.1002/qj.49710243212. - and _ 1983: On plume rise within a convective boundary layer. Atmos. Environ., 17, 2435-2447, https://doi.org/10.1016/ 0004-6981(83)90068-9.
- - and — 1987: Buoyant plume dispersion and inversion entrapment in and above a laboratory mixed layer. Atmos. Environ., 21, 1725-1735, https://doi.org/10.1016/0004-6981(87) 90111-9.

Woods, A. W., 2010: Turbulent plumes in nature. Annu. Rev. Fluid. Mech., 42, 391-412, https://doi.org/10.1146/annurev-fluid-121108145430.

Wyngaard, J., 1984: Large-eddy simulation: Guidelines for its application to planetary-boundary layer research. U.S. Army Research Office Tech. Rep. 0804, 20 pp. 